\title{
High-resolution Med-CORDEX regional climate model simulations for hydrological impact studies: a first evaluation of the ALADIN-Climate model in Morocco
}

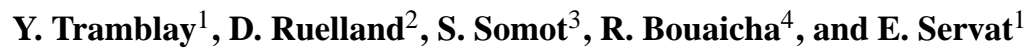 \\ ${ }^{1}$ IRD - HydroSciences Montpellier, UMR5569, Maison des Sciences de l'Eau, Place Eugène Bataillon, \\ 34095 Montpellier Cedex 5, France \\ ${ }^{2}$ CNRS - HydroSciences Montpellier, UMR5569, Maison des Sciences de l'Eau, Place Eugène Bataillon, \\ 34095 Montpellier Cedex 5, France \\ ${ }^{3}$ CNRM-GAME, Météo-France, Centre National de Recherches Météorologiques, 42 avenue G. Coriolis, \\ 31057 Toulouse cedex 1, France \\ ${ }^{4}$ Direction de la Recherche et de la Planification de l'Eau, Rue Hassan Benchekroune, Agdal, Rabat, Morocco \\ Correspondence to: Y. Tramblay (yves.tramblay@ird.fr)
}

Received: 25 April 2013 - Published in Hydrol. Earth Syst. Sci. Discuss.: 3 May 2013

Revised: 26 July 2013 - Accepted: 12 August 2013 - Published: 2 October 2013

\begin{abstract}
In the framework of the international CORDEX program, new regional climate model (RCM) simulations at high spatial resolutions are becoming available for the Mediterranean region (Med-CORDEX initiative). This study provides the first evaluation for hydrological impact studies of one of these high-resolution simulations in a $1800 \mathrm{~km}^{2}$ catchment located in North Morocco. Different approaches are compared to analyze the climate change impacts on the hydrology of this catchment using a high-resolution RCM (ALADIN-Climate) from the Med-CORDEX initiative at two different spatial resolutions (50 and $12 \mathrm{~km}$ ) and for two different Radiative Concentration Pathway scenarios (RCP4.5 and RCP8.5). The main issues addressed in the present study are: (i) what is the impact of increased RCM resolution on present-climate hydrological simulations and on future projections? (ii) Are the bias-correction of the RCM model and the parameters of the hydrological model stationary and transferable to different climatic conditions? (iii) What is the climate and hydrological change signal based on the new Radiative Concentration Pathways scenarios (RCP4.5 and RCP8.5)? Results indicate that high resolution simulations at $12 \mathrm{~km}$ better reproduce the seasonal patterns, the seasonal distributions and the extreme events of precipitation. The parameters of the hydrological model, calibrated to reproduce runoff at the monthly time step over the
\end{abstract}

1984-2010 period, do not show a strong variability between dry and wet calibration periods in a differential split-sample test. However the bias correction of precipitation by quantilematching does not give satisfactory results in validation using the same differential split-sample testing method. Therefore a quantile-perturbation method that does not rely on any stationarity assumption and produces ensembles of perturbed series of precipitation was introduced. The climate change signal under scenarios 4.5 and 8.5 indicates a decrease of respectively -30 to $-57 \%$ in surface runoff for the mid-term (2041-2062), when for the same period the projections for precipitation are ranging between -15 and $-19 \%$ and for temperature between +1.3 and $+1.9^{\circ} \mathrm{C}$.

\section{Introduction}

The most common approach for hydrological impact studies of climate change is to run hydrological models with climate scenarios, usually provided by the outputs of precipitation and temperature from climate models downscaled or corrected to the catchment of interest (Etchevers et al., 2002; Fowler et al., 2007; Chiew et al., 2009; Senatore et al., 2011; Ruelland et al., 2012). It is acknowledged that in this approach the main source of uncertainty is the global 
climate model and the downscaling method rather than the hydrological model (Quintana Seguí et al., 2010; Teng et al., 2012). Many studies have applied this framework for impact studies across the world. But fewer studies have been conducted so far in countries in the Mediterranean basin, yet considered a hotspot of climate change (Giorgi, 2006; Giorgi and Lionello, 2008; Milano et al., 2013). The Mediterranean region is a transition zone between arid and temperate climates with several mountainous areas, therefore a complex climate system affected by the interactions between midlatitude and sub-tropical processes. The new generation of regional climate model simulations dedicated to the Mediterranean area such as those provided by the Med-CORDEX initiative (www.medcordex.eu, Ruti et al., 2013; Herrmann et al., 2011) in the line with the CMIP5 and CORDEX programs aims at increasing the reliability of past and future regional climate information and understanding the processes that are responsible for the Mediterranean climate variability and trends.

Climate change impacts on the hydrology of Mediterranean catchments have been evaluated mainly for catchments located in France (Quintana Seguí et al., 2010), Spain (Majone et al., 2012), Italia (Senatore et al., 2011) and at the Mediterranean scale (Sanchez-Gomez et al., 2009; Dubois et al., 2012; Milano et al., 2012, 2013) but no studies to our knowledge have considered in detail the case of North African catchments. In Northern Morocco, the rainiest part of the country, are located most of the storage-dams for water management (Bouaicha and Benabdelfadel, 2010). This region may be particularly affected by climate change, since several studies have shown that precipitation is likely to decrease between -10 and $-20 \%$, while temperatures are likely to rise between 2 and $3{ }^{\circ} \mathrm{C}$ by 2050 (Ragab and Prudhomme, 2002; Born et al., 2008; Driouech et al., 2010; Patricola and Cook, 2010; Schilling et al., 2012; Milano et al., 2012, 2013). These changes will likely have a strong effect in Morocco where the agricultural sector is of high importance for the country's economy and very dependent on surface water resources (Bouaicha and Benabdelfadel, 2010; Schilling et al., 2012). Therefore, there is a need to quantify the possible climate change impacts on the water resources of this region. In this study different methods are evaluated to analyze the climate change effects on the hydrology of the Makhazine catchment, the 6th largest dam of Morocco, using a high-resolution regional climate model (RCM) ALADINClimate from the MED-CORDEX initiative at two different spatial resolution (50 and $12 \mathrm{~km}$ ) and for two different Radiative Concentration Pathway scenario (RCP4.5 and RCP8.5).

Most often, a top-down downscaling approach is adopted for hydrological impact studies, i.e. downscaling and/or bias correcting global climate models (GCM) or RCM outputs to the catchment of interest (Fowler et al., 2007; Maraun et al., 2010). To resolve the mismatch of scale between GCMs and the scale relevant for regional impacts studies, recent RCMs such as those the Med-CORDEX project provide a resolution now reaching up to a few tenths of kilometers. With their increased spatial resolution, they aim at better representing orography and the associated climatic processes especially in complex terrain, such as the Mediterranean basin (Driouech et al., 2009). Nonetheless, they usually require a bias correction of their outputs (Déqué, 2007; Piani et al., 2010). Several studies have shown that empirical quantile-mapping methods usually outperform other approaches (Themeßl et al., 2011) but Lafon et al. (2012) noticed that the results were very sensitive to the choice of calibration time period. Indeed the strong assumption behind bias correction is that the model bias is stationary in time (Maraun et al., 2010). This hypothesis is impossible to verify for future horizons of climate not yet observed. However this assumption can be tested in present climate by comparing the model bias during different periods (Maraun et al., 2010; Themessl et al., 2011; Vrac et al., 2012). This type of assessment was performed by Maraun (2012) for RCM simulations of the ENSEMBLES project. He showed that the precipitation bias is stationary for most parts of Europe, but strongly affected by variability in arid and semi-arid regions such as Maghreb. For regions where precipitation occurs as rather rare and localized events, internal variability may dominate the estimated seasonal biases on a local scale even when averaging over $30 \mathrm{yr}$ (Maraun, 2012). In addition it has been proved for Morocco at least that bias in RCMs could be weather regime dependent (Driouech et al., 2010).

Beside the direct application of climate model outputs after downscaling or bias-correction into hydrological models, different bottom-up methods also exist (Prudhomme et al., 2010). The so-called "delta change" or perturbation method belongs to this type of approach (Anandhi et al., 2011; Ruelland et al., 2012): it consists in perturbing the observed precipitation and temperature series to reproduce the changes observed between the control and future climatic simulations from climate models. The hypothesis behind is that climate models are not necessarily good at reproducing the present climate in a realistic manner (contrary to weather forecast models, they do not assimilate observations for example) but are mainly designed to simulate the trends of the earth climate system related to external forcing (green-house gases, aerosols, solar variation, volcanic eruption). Most often, the method relies on monthly change factors (Ruelland et al., 2012) but this approach does not account for the possible changes in the high-order moments of the distribution other than the mean. Therefore, it may not be efficient for semi-arid regions such as North Africa, with a small number of rainy days and monthly totals often driven by extreme precipitation events (Tramblay et al., 2012a). Variants of the method have been proposed, that take into account the whole distribution changes by modifying each quantile by a different change factor (Chiew et al., 2009; Liu et al., 2011; Willems and Vrac, 2011).

Several studies have warned about the use of calibrated model parameters for different climatic conditions (Wilby, 
2005; Vaze et al., 2010; Coron et al., 2012). These studies in different regions of the globe highlight the need for robust calibration approaches for hydrological models in order to evaluate future climate change impacts. The main conclusion that could be drawn from these studies is that the stability in time of model parameters could vary from one site to another, consequently there is a need for long time series to test the model on sub-period representatives of different climatic characteristics, to better quantify the uncertainties (Vaze et al., 2010; Coron et al., 2012; Li et al., 2012). It must be noted that this consideration is not new: Klemes (1986) advocated the use of a differential split-sample test (DSST) procedure to validate hydrological models. The DSST approach relies on choosing calibration and validation time slices with different climatic features (wet or dry years for instance). That way, hydrological models are validated with the most stringent settings, thereby providing an efficient way to assess the time stability of their parameters.

In the present study the outputs of a RCM from the MedCORDEX project at different spatial resolutions are considered, together with different methods to evaluate the future changes on surface water resources. Due to limited data availability, a conceptual lumped hydrological model is chosen. Different downscaling approaches are tested, including the direct application of RCM outputs, a quantile-mapping bias correction method and a quantile-perturbation approach. The purpose of this study is not to give a complete diagnostic of the future projections but to review different approaches relevant to conduct hydrological impact studies with high resolution RCMs in the semi-arid catchments of North Africa. Several methodological issues that have never been investigated for this region are addressed in the present study for a medium-size catchment in Morocco, in particular:

1. What is the climate and hydrological change signal simulated by regional climate model (RCM) based on the new Radiative Concentration Pathways scenarios (RCP4.5 and RCP8.5) used in CMIP5?

2. What is the impact of the resolution of the RCM on hydrological simulations and future projections?

3. Are the bias-correction for RCM simulations and the hydrological model parameters stationary and transferable to different climatic conditions (wet to dryer or dry to wetter conditions)?

To achieve these goals, we decided to investigate very recent dynamical downscaling simulations performed in the frame of the CORDEX program (http://wcrp-cordex.ipsl. jussieu.fr/, Giorgi et al., 2009; Colin et al., 2010) for the Mediterranean region (Med-CORDEX, www.medcordex.eu, Ruti et al., 2013) with one RCM (the French ALADINClimate developed at Météo-France, CNRM). Evaluation (reanalysis as lateral boundary conditions) and scenarios (CMIP5 model as lateral boundary conditions) simulations are available as well as twin simulations with two different spatial resolution (the standard $50-\mathrm{km}$ and the frontier 12-km) and two different emission gas scenarios (optimistic RCP4.5 and pessimistic RCP8.5). To our knowledge, the $12-\mathrm{km}$ scenario simulations used here are the higherresolution simulations ever used to study climate change over the Mediterranean area. It is why we chose this ensemble of runs particularly designed to address the issues listed above.

\section{Study area and datasets}

\subsection{Hydro-climatic data over the reference period}

The catchment of the Makhazine dam in North Morocco drains an area of $1808 \mathrm{~km}^{2}$ (Fig. 1) under a Mediterranean climate, with a wet season with moderate temperatures from October to April and a hot dry season from May to September (Tramblay et al., 2012b). The regional climate is influenced by large scale circulation, Knippertz et al. (2003) found a relationship between monthly precipitation and the storm tracks over the Atlantic, related to the North Atlantic Oscillation (NAO). It is also supported by Esper et al. (2007), that the droughts are related to the NAO and Atlantic sea surface temperatures.

The basin consists of plains in the western part, while in the east the terrain becomes more rugged and mountainous, the altitude increases progressively eastward until reaching $1745 \mathrm{~m}$ a.s.l. The Makhazine dam was built in 1979 for irrigation, water supply, energy production, and protection against floods. It is a mixed earth and rocks dam, creating a reservoir with a storage capacity of $724 \times 10^{6} \mathrm{~m}^{3}$ (the 6th largest of Morocco). Because of the influence of the Atlantic Ocean, the basin receives $1100 \mathrm{~mm}$ of precipitation per year on average but with a strong inter-annual variability. The mean annual runoff generated is $460 \mathrm{~mm}$, producing a dam inflow of $760 \times 10^{6} \mathrm{~m}^{3}$ and the mean evaporation measured at the dam reservoir is $1176 \mathrm{~mm} \mathrm{yr}^{-1}$.

The dam inflow is measured daily since 1984 at the Makhazine station. The monthly mean air temperatures (between 1975 and 1996), pan evaporation (between 1984 and 2011), precipitation (between 1980 and 2010) and discharge (between 1984 and 2010) are shown in Fig. 2. 11 stations with daily precipitation $(P)$ located within and outside the catchment were considered (Fig. 1). The study period is 19842010 (27 hydrological years from September to August). The rainfall depth at the catchment scale was obtained through spatial interpolation with the Thiessen approach. No trends were detected in precipitation or temperature data aggregated over annual or monthly time steps between 1984 and 2010. However there is a significant trend in annual temperatures from 1975 to 1982 (Fig. 2), according to the MannKendall trend test at the $5 \%$ significance level. The individual precipitation records at each station have been carefully checked to remove unrealistic values and identify the missing days/periods. 


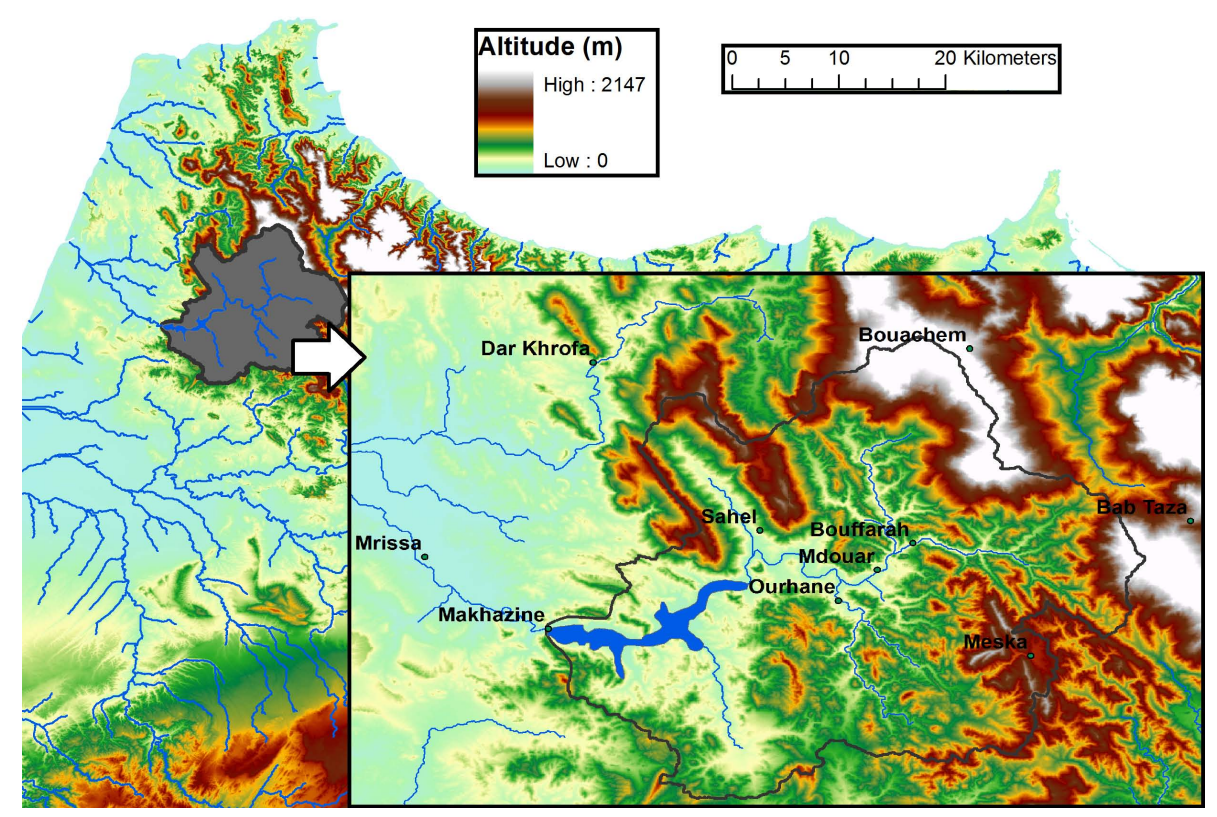

Fig. 1. The Makhazine catchment and location of the rain gauge stations.
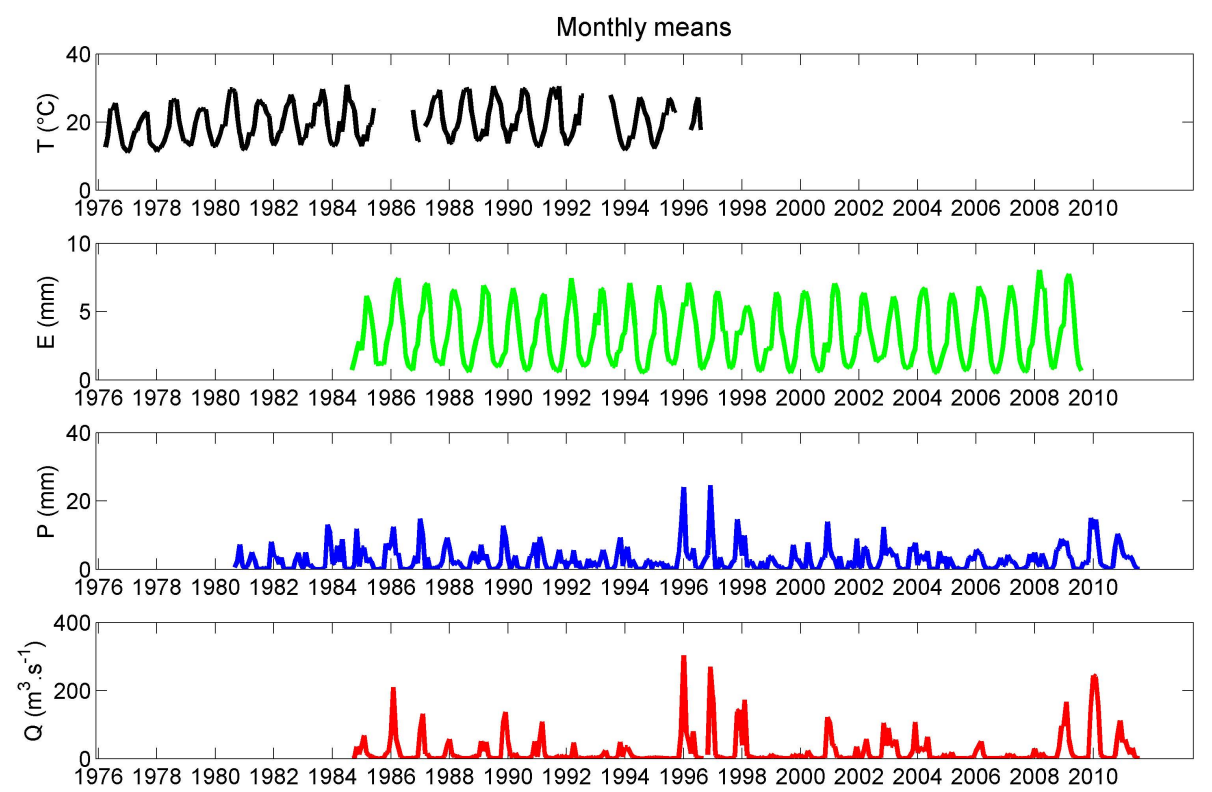

Fig. 2. Monthly mean air temperature, pan evaporation, precipitation and discharge for the full length of records available.

\subsection{Regional climate simulations from MEDCORDEX}

\subsubsection{The ALADIN-climate regional climate model}

We used the limited-area atmosphere RCM ALADINClimate (Radu et al., 2008; Colin et al., 2010; Herrmann et al., 2011) in its version 5 firstly described in Colin et al. (2010). ALADIN-Climate shares the same dynamical core as the cycle 32 of its weather forecast ALADIN (Aire Limitée Adaptation dynamique Développe- ment InterNational) counterpart and the same physical package as the version 5 of the GCM ARPEGEClimate (see Déqué, 2010 or http://www.cnrm.meteo.fr/ gmgec/arpege-climat/ARPCLI-V5.1/index.html). ALADINClimate is a bi-spectral RCM with a semi-implicit semilagrangian advection scheme. Horizontal diffusion, semiimplicit corrections and horizontal derivatives are then computed with a finite family of analytical functions. In the case of ALADIN, a 2-D bi-Fourier decomposition is used. Contrary to the global model Arpege, the RCM grid is 
Table 1. Description and time periods for the different simulations of the ALADIN-Climate Regional Climate Mode used in the current study.

\begin{tabular}{lllc}
\hline Time periods & Acronym & $\begin{array}{l}\text { Lateral } \\
\text { boundary } \\
\text { conditions }\end{array}$ & $\begin{array}{c}\text { Spatial } \\
\text { resolution }\end{array}$ \\
\hline $\begin{array}{llll}\text { Evaluation runs } \\
(1984-2010)\end{array}$ & MED11-EVAL & ERA-Interim & $12 \mathrm{~km}$ \\
\hline Historical runs & MED11-HIST & CNRM-CM5 & $12 \mathrm{~km}$ \\
$(1984-2005)$ & MED44-HIST & CNRM-CM5 & $50 \mathrm{~km}$ \\
\hline Scenario runs & MED11-RCP4.5 & CNRM-CM5 & $12 \mathrm{~km}$ \\
$(2041-2062)$ & MED44-RCP4.5 & CNRM-CM5 & $50 \mathrm{~km}$ \\
& MED11-RCP8.5 & CNRM-CM5 & $12 \mathrm{~km}$ \\
& MED44-RCP8.5 & CNRM-CM5 & $50 \mathrm{~km}$ \\
\hline
\end{tabular}

not periodic, so a bi-periodicization is achieved in gridpoint space by adding a so-called extension zone used only for Fourier transforms. The non-linear contributions to the equations are performed in grid point space. In this configuration ALADIN-Climate includes an 11-point wide biperiodization zone in addition to the more classical 8 point relaxation zone using the Davies technique. More details on the physical parameterizations of ALADIN-Climate version 5 can be found in the above cited references and web site. It is worth noting that ALADIN-Climate takes into account five greenhouse gases $\left(\mathrm{CO}_{2}, \mathrm{CH}_{4}, \mathrm{~N}_{2} \mathrm{O}\right.$ and $\left.\mathrm{CFC}\right)$ in addition to water vapour and ozone. The scheme also takes into account five classes of aerosols. More details about the behaviour of ALADIN-Climate can be found in the literature for academic studies using the Big-Brother framework (Radu et al., 2008; Colin et al., 2010), for the Mediterranean Sea water budget (Sanchez-Gomez et al., 2011) and for extreme precipitation (Déqué and Somot, 2008; Colin et al., 2010; Vrac et al., 2012). The version 5 is used in the framework of the regional CORDEX exercise (Mediterranean, Africa, North America areas) and is close to the ARPEGE-Climate version used in the CMIP5 exercise. Previous version of ALADIN-Climate (version 4) was used for the European ENSEMBLES project in which it was inter-compared with the state-of-the art of the European RCMs at 50 and $25 \mathrm{~km}$ (Christensen et al., 2010).

For the model definition, we used a Lambert conformal projection for pan-Mediterranean area at horizontal resolutions of $50 \mathrm{~km}($ resp. $12 \mathrm{~km})$ centred at $14,43^{\circ} \mathrm{N}$ with 128 (resp. 432) grid points in longitude and 90 (resp. 288) grid points in latitude including the bi-periodization (11) and the relaxation zone $(2 \times 8)$. The model version has 31 vertical levels. The time step used is $1800 \mathrm{~s}$ (resp. $600 \mathrm{~s}$ ). This geographical set-up allows the Med-CORDEX official area (www.medcordex.eu) to be fully included in the model central zone.

\subsubsection{The regional climate simulations}

Two twin families of four simulations available with the ALADIN-Climate RCM were used in the current study (Table 1). The eight simulations share the same area and the same physics except for few tunings related to the resolution change. The families differ only by the spatial resolution: the standard runs are performed at a $50-\mathrm{km}$ resolution which is the CORDEX standard for the CORE runs, while the very high-resolution RCM runs are performed at a frontier resolution of 12-km over the whole Mediterranean area. To our knowledge, the 12-km scenario simulations used here are the higher-resolution simulations ever used to study climate change over the Mediterranean area. Déqué and Somot (2008) and Herrmann et al. (2011) proved that $12-\mathrm{km}$ resolution is required to represent accurately extreme precipitation over land in the Mediterranean climate of France and extreme and coastal wind over the Mediterranean Sea. We recall that for the Mediterranean basin, Gibelin and Déqué (2003) used the first scenario simulation at 50-km whereas Gao et al. (2006) used a $20-\mathrm{km}$ resolution for the first time.

Each family is composed by four simulations:

1. The so-called evaluation run in which the RCM is driven at its lateral boundary conditions by the ERAInterim reanalysis $(80-\mathrm{km}$ at its full resolution) (Dee et al., 2011). The period simulated is 1979-2012 (minimal CORDEX period is 1989-2008). The period 1984-2010 is used in the current study for model evaluation. The climate as simulated by ALADIN-Climate in the "evaluation mode" is the most realistic representation of the climate simulated, as we consider that ERA-Interim is the best knowledge of the 4-D dynamic of the atmosphere available over the last $30 \mathrm{yr}$.

2. The historical run in which the RCM is driven by the historical run of a CMIP5 GCM. We used CNRMCM5 (Voldoire et al., 2011) developed at CNRM to ensure a consistency of the physics between the driving GCM and the driven RCM. Note that consistency is however not perfect as the land-surface scheme and the radiative scheme are slightly different. However solar forcing, aerosol field and GHG concentrations are similar in the RCM and GCM. After a 2-yr spinup of ALADIN to ensure the stability of the landsurface scheme, the historical run covers the period 1950-2005. Among the 10-member runs with CNRMCM5, we chose main member of CNRM-CM5 called HISTr8.

3. The RCP4.5 scenario in which ALADIN-Climate is driven by the RCP4.5 scenario run made with CNRMCM5 and corresponding to HISTr8 historical run. The period covered is $2006-2100$. 
4. The RCP8.5 scenario in which ALADIN-Climate is driven by the RCP8.5 scenario run made with CNRMCM5 and corresponding to HISTr8 historical run. The period covered is 2006-2100.

RCP4.5 and RCP8.5 corresponds to the naming of two of the new climate change scenarios (Radiative Concentration Pathway scenario) used in CMIP5 and in the IPCC-AR5. They replace the former SRES scenarios used for example in CMIP3 and IPCC-AR4. The RCP4.5 (resp. RCP8.5) means that the GHG and aerosols concentrations evolves in a way that leads to an additional radiative forcing equal to $+4.5 \mathrm{~W} \mathrm{~m}^{-2}$ (resp. $+8.5 \mathrm{~W} \mathrm{~m}^{-2}$ ) at the end of the 21 st century with respect to the pre-industrial climate. Consequently the RCP4.5 can be considered as an optimist scenario with respect to the GHG concentration whereas RCP8.5 is a more pessimistic option.

The 8 simulations performed with ALADIN-Climate and used in the current study (Table 1) are part of the MedCORDEX exercise that is the Mediterranean domain (one of the 12 official domains) of the CORDEX program. To summarize, CORDEX is the CMIP5 counterpart for the RCM. More information can be found on CORDEX in Giorgi et al. (2009) and Colin et al. (2010) (see also http: //wcrp-cordex.ipsl.jussieu.fr/) and on Med-CORDEX in Ruti et al. (2013) or at www.medcordex.eu.

For the different simulations, the different grid meshes covering the catchment area have been averaged according to the fraction of catchment coverage, to be consistent with the Thiessen interpolation method used for observed precipitation. Indeed it is worth noting that at a $12-\mathrm{km}$ resolution, 9 grid meshes are inside the catchment of interest whereas, at a $50-\mathrm{km}$ resolution, the catchment is smaller than one single grid mesh $\left(2500 \mathrm{~km}^{2}\right)$.

\section{Methods}

\subsection{Hydrological modelling}

The hydrological model considered is the GR4J, a conceptual lumped model developed by Perrin et al. (2003). GR4J simulates runoff via two functions. First, a production function that accounts for precipitation (net precipitation) and evapotranspiration, determines the precipitation fraction (effective precipitation) participating to flow and supplying the production reservoir (interception and percolation). Next, a routing function calculates runoff at the catchment outlet. The four parameters of the model were calibrated with daily discharge measured at the dam using unconstrained nonlinear optimization with the simplex search method (Lagarias et al., 1998). A warm-up period of 365 days was considered for the correct initialization of the production reservoir. The model was run at a daily time step but evaluated at the monthly time step, since the goal of the study is focused on water resources and not day-to-day variability. In this study, two objectives were considered: (i) a good agreement between the simulated and observed hydrographs; and (ii) a good agreement between the simulated and observed catchment runoff volume. Therefore, the multi-objective function, for which the lowest value indicate a good model agreement with observations, combines the Nash-Sutcliffe efficiency coefficient (NSE) on simulated mean monthly discharge and the bias (BIAS) on runoff volume over the full time period considered:

$f=(1-\mathrm{NSE})(1+|\mathrm{BIAS}|)$.

This function gives weight to both dynamic representation and water balance (Coron et al., 2012; Ruelland et al., 2012). The hydrological model was calibrated and validated using a differential split-sample test (DSST, Klemes, 1986): The model was calibrated on the wet years and validated on dry years, and inversely. The DSST is a robust approach to validate the model in the most extreme conditions, it is recommended for climate change impact studies (Vaze et al., 2010; Coron et al., 2012). To identify the dry and wet years (Fig. 3), annual total precipitation was first computed for each hydrological year (from September to August), then the annual values were sorted: as a result, the wet years $(14 \mathrm{yr})$ are those above the median annual precipitation $\left(896 \mathrm{~mm} \mathrm{yr}^{-1}\right)$, the dry years are those below the median $(13 \mathrm{yr})$. The selected dry years have on average $-45 \%$ less precipitation than the wet years. Here a standard split-sample test (SST) would not be very meaningful to test the model in a climate change context since in the present study area the calibration and validation periods would have very similar characteristics, in the absence of long time trends in precipitation, discharge or evapotranspiration.

Different computation methods for Potential Evapotranspiration (PE) exist, but several studies have shown the minor influences of the different formula on resulting river flow (Oudin et al., 2005; Sperna Weiland et al., 2012). The formula proposed by Oudin et al. (2005) for evapotranspiration is efficient for climate change impact studies since it relies only on air temperature (Kay and Davies, 2008; Ruelland et al., 2012). It was computed using the mean monthly air temperature data available at the Makhazine station. In a preliminary sensitivity analysis, the hydrological model has been forced by: (a) the evaporation measured daily at the dam, (b) Monthly PE computed with monthly air temperatures (between 1984 and 1996), (c) mean monthly PE computed with mean monthly air temperatures and (d) mean monthly PE computed with mean monthly air temperatures interpolated over the catchment considering a temperature gradient of $-6.5^{\circ} \mathrm{C}$ per kilometer, which is consistent with specific works by Boudhar et al. (2010) on Moroccan High-Atlas. The results (not shown here) indicated very similar simulations using the 3 different PE inputs. This shows that the intra-annual variations in evapotranspiration are much more important than the inter-annual variations. Since no trends were detected in monthly air temperatures or in the measured evaporation at the dam, the method $\mathrm{c}$ was selected for the computation of PE. 


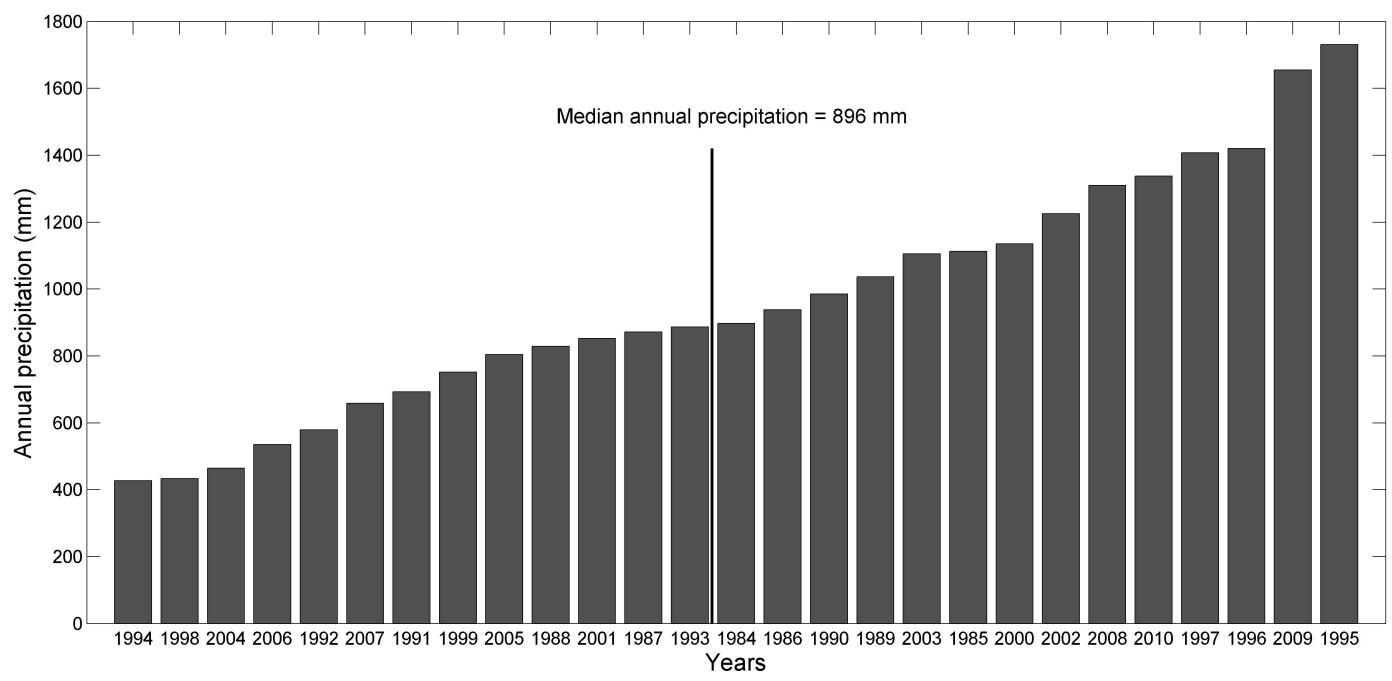

Fig. 3. Precipitation amounts during dry and wet years, sorted in ascending order.

\subsection{Downscaling methods}

Different options were tested to incorporate the climate change signal from the climate model into the hydrological model. Since only monthly temperatures were available at one station and because the hydrological model was very little sensitive to the different PE inputs tested, the changes in temperature were incorporated into the hydrological simulations by a monthly change factor between the present period and the future period. This is a common practice when hydrological simulations are much more sensitive to the precipitation inputs than to temperature (Liu et al., 2011). Therefore the following two methods apply only for the precipitation outputs of the climate model.

\subsubsection{Bias correction of precipitation}

The bias correction of precipitation was performed using a quantile-mapping method. The "Cumulative Distribution Function-transform" (CDF-t) method developed by Michelangeli et al. (2009) was considered (freely available on www.r-project.org/). CDF-t is a variant of the quantilequantile correction method between climate model and observed CDFs (Déqué, 2007; Piani et al., 2010; Themeß1 et al., 2011; Lafon et al., 2012). It takes into account the changes between the historic and the future time period, while quantile-quantile projects the simulated values onto the historic CDF to compute and match quantiles (Michelangeli et al., 2009; Lavaysse et al., 2012; Vrac et al., 2012). In CDF-t, if the model CDF is off range of the observed $\mathrm{CDF}$, a constant correction method is applied as proposed by Déqué (2007). If applied on GCM data, it performs a change of spatial scale and could be seen as a downscaling approach (Vrac et al., 2012). If applied on RCM data with the same resolution as the observation network, as it is the case in the present study, it can be seen as a bias correction method. In the CDF-t approach, a transformation $T$ is applied during an historical period to the $\mathrm{CDF}$ of the climate model $\left(F_{\mathrm{MH}}\right)$ to define a new $\mathrm{CDF}$ as close as possible to the observed CDF $\left(F_{\mathrm{OH}}\right)$ :

$T\left(F_{\mathrm{MH}}(x)\right)=F_{\mathrm{OH}}(x)$.

By replacing $x$ by $F_{\mathrm{MH}}^{-1}(u)$, with $u$ any probability between [0 1]:

$T(u)=F_{\mathrm{OH}}\left(F_{\mathrm{MH}}^{-1}(u)\right)$

which provides a definition of $T$. Under the assumption that $T$ is stationary between the historical and future periods (Vrac et al., 2012), the transformation can be applied to $F_{\mathrm{MF}}$, the climate model CDF over a future period, to generate $F_{\mathrm{OF}}$, the future CDF of the variable of interest (here catchment precipitation):

$T\left(F_{\mathrm{MF}}(x)\right)=F_{\mathrm{OF}}(x)$.

This approach was applied on strictly positive daily precipitation each month, to take into account the seasonality since the CDF require independent and identically distributed samples. Since the climate models usually simulate too many drizzle days, a new precipitation threshold larger than zero was selected for the RCM simulations (Lavaysse et al., 2012). This new threshold was defined in order to keep the same number of wet days in the RCM and in observations during the historical period. For example with the MED11EVAL simulation the new thresholds for dry days vary from $0.01 \mathrm{~mm}$ during the wettest month (December) to $0.96 \mathrm{~mm}$ during the driest month (August). Experiments with a fixed threshold set at $0.1 \mathrm{~mm}$ day $^{-1}$ were also performed, providing fully equivalent results as those presented in Sect. 4.3. 
In several hydrological impact studies, the stationary hypothesis is not validated properly, under the argument that it is not verifiable for future time horizons (Quintana Segu/'i et al., 2010; Ehret et al., 2012). However this hypothesis is verifiable, at least during historical periods, as performed by Themeßl et al. (2011), Lafon et al. (2012), Vrac et al. (2012) and Maraun (2012). In the current study, the stationary hypothesis of the bias correction performed with CDF-t was verified using the DSST and SST methods. Validation was performed using quantiles-quantiles plots and the Kolmorogov-smirnov test between the observed and bias-corrected precipitation CDFs.

\subsubsection{Quantile perturbation}

A quantile perturbation method does not consider the differences between observed and simulated datasets but only the relative changes between past and future time periods as simulated by climate models. Therefore it belongs to the family of the so called "Delta change" methods (Willems and Vrac, 2011). Several authors have implemented this method for hydrological impact studies (Chiew et al., 2009; Liu et al., 2011; Willems and Vrac, 2011): we introduced a variant that is producing random ensembles of perturbed series, to prevent that a single random generation may contain outliers. The computation was done for each month separately, between an observed period (CTRL), a simulation during the observation period (SIM) and a projected future period (PROJ). The approach followed these steps:

1. identification of the frequency of dry days (when $P<0.1 \mathrm{~mm}$ ) in CTRL, SIM and PROJ;

2. if the amount of dry days increases between SIM and PROJ, the corresponding amount of additional wet days in CTRL were randomly changed into dry days (100 randomly perturbed series (PERT) were generated);

3. if the amount of dry days decreases between SIM and PROJ, the corresponding amount of dry days was randomly changed into wet days in CTRL. The "new" wet days are randomly selected from wet days in CTRL (100 randomly perturbed series (PERT) were generated);

4. for each PERT series perturbed in steps 2 or 3, the empirical quantiles were adjusted by the change factor $(\mathrm{CF})$ between the PROJ and SIM quantiles for the corresponding probabilities $p$ :

$$
\mathrm{CF}_{\mathrm{p}}=\frac{Q_{\mathrm{PROJ}_{\mathrm{p}}}}{Q_{\mathrm{SIM}_{\mathrm{p}}}} .
$$

Spline interpolation was applied when different sets of empirical probabilities $p$ were obtained for SIM and PROJ.
Then, the ensemble of perturbed series obtained were used as inputs of the hydrological model. The mean of the resulting runoff simulations was considered for evaluating the climate change impacts on monthly discharges, thus avoiding the use of a single randomly perturbed series.

\section{Results}

\subsection{Evaluation of RCM simulations at different resolutions}

Although past model performance to reproduce the observed climate does not imply better skills for future projections, more confidence can be put into models able to reproduce the key characteristics of climate. The precipitation outputs of the RCM simulations are compared with the observed precipitation and temperature records. Figure 4 shows the results for the ALADIN model driven by ERA-Interim during the evaluation period: the monthly cycle of precipitation and the CDF of monthly precipitation between 1984 and 2010. The same plots are shown in Fig. 5 but with the ALADIN model driven by CNRM-CM5 during the historical period (1984-2005). For MED11-EVAL, the high-resolution model at $12 \mathrm{~km}$, there is a much better reproduction of the seasonal cycle and the seasonal CDFs than with MED44-EVAL $(50 \mathrm{~km})$, except for the summer: however, the results for this season are difficult to evaluate due to the very limited amount of rain days. Indeed, during the period 1984-2010, there are $91 \%$ of dry days for JJA ( $61 \%$ for SON, $52 \%$ for DJF and $60 \%$ for MAM) in observed precipitation. The results are similar with ALADIN forced by CNRM-CM5, in particular for the wet season (SON and DJF), showing the improvement in reproducing the observed patterns with the high-resolution model (MED11-HIST). However the seasonal precipitation cycle tends to be shifted towards maximum precipitation in February in the simulations, instead of December.

The most extreme precipitation events (i.e. exceeding the 95th percentile) are much better reproduced in the high resolutions runs (MED11-EVAL and MED11-HIST). However during the MAM and JJA seasons there is a strong positive bias (overestimation of precipitation) in particular during the dry season (JJA). This overestimation probably comes from the GCM CNRM-CM5 forcing (lateral or surface) as it is the only difference between MED11-HIST and MED11-EVAL. To evaluate if the precipitation bias was comparable during wet or dry years, the relative bias on precipitation totals for MED11-EVAL and MED44-EVAL was computed. Results are shown in Fig. 6: except during summer months, the bias is not strongly different between dry and wet periods, with a difference less than $5 \%$ in most cases.

For the temperature, the comparison with observed data is limited since only mean monthly temperatures at the Makhazine station are available. The comparison is performed here with the monthly temperatures interpolated at 

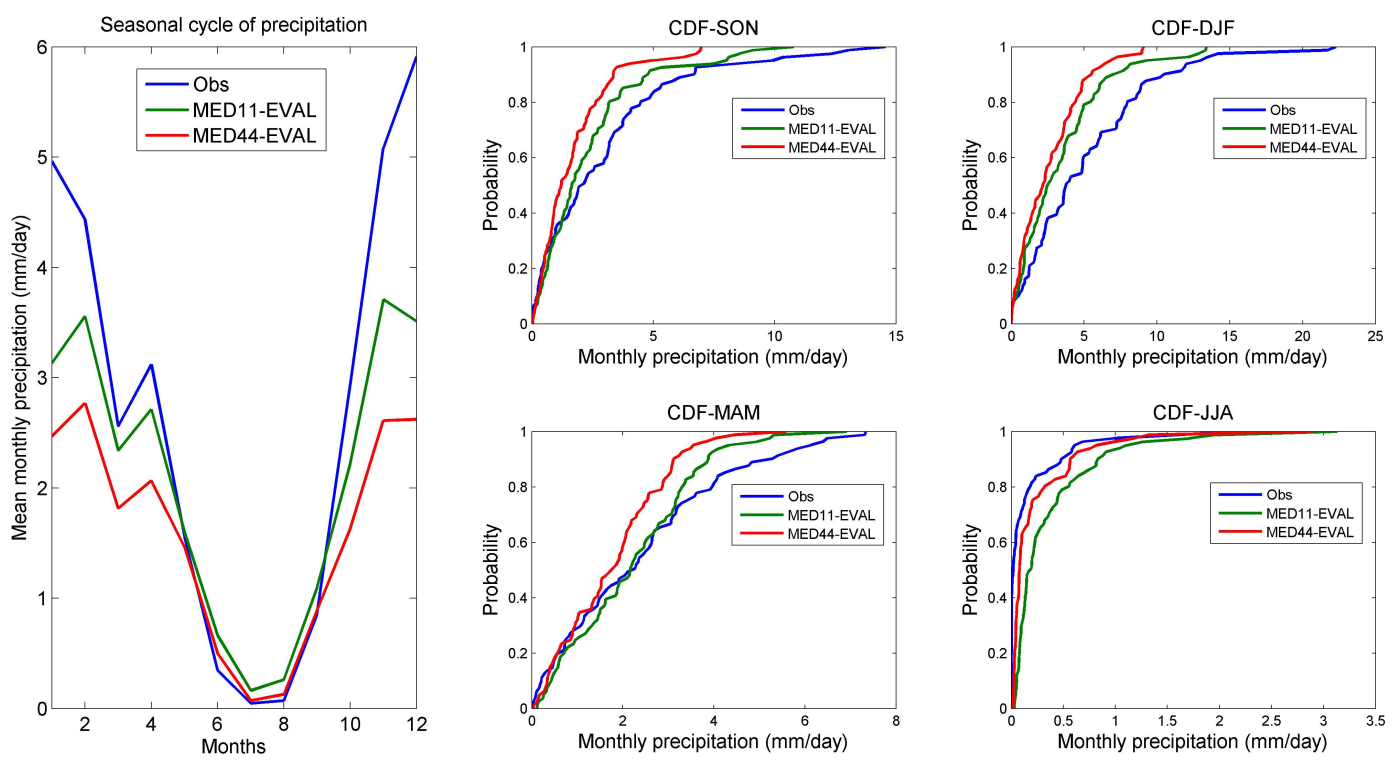

Fig. 4. Evaluation of the seasonal cycle (left panel) and seasonal cumulative distributions of monthly precipitation (right panels) of MED11EVAL and MED44-EVAL (1984-2010).
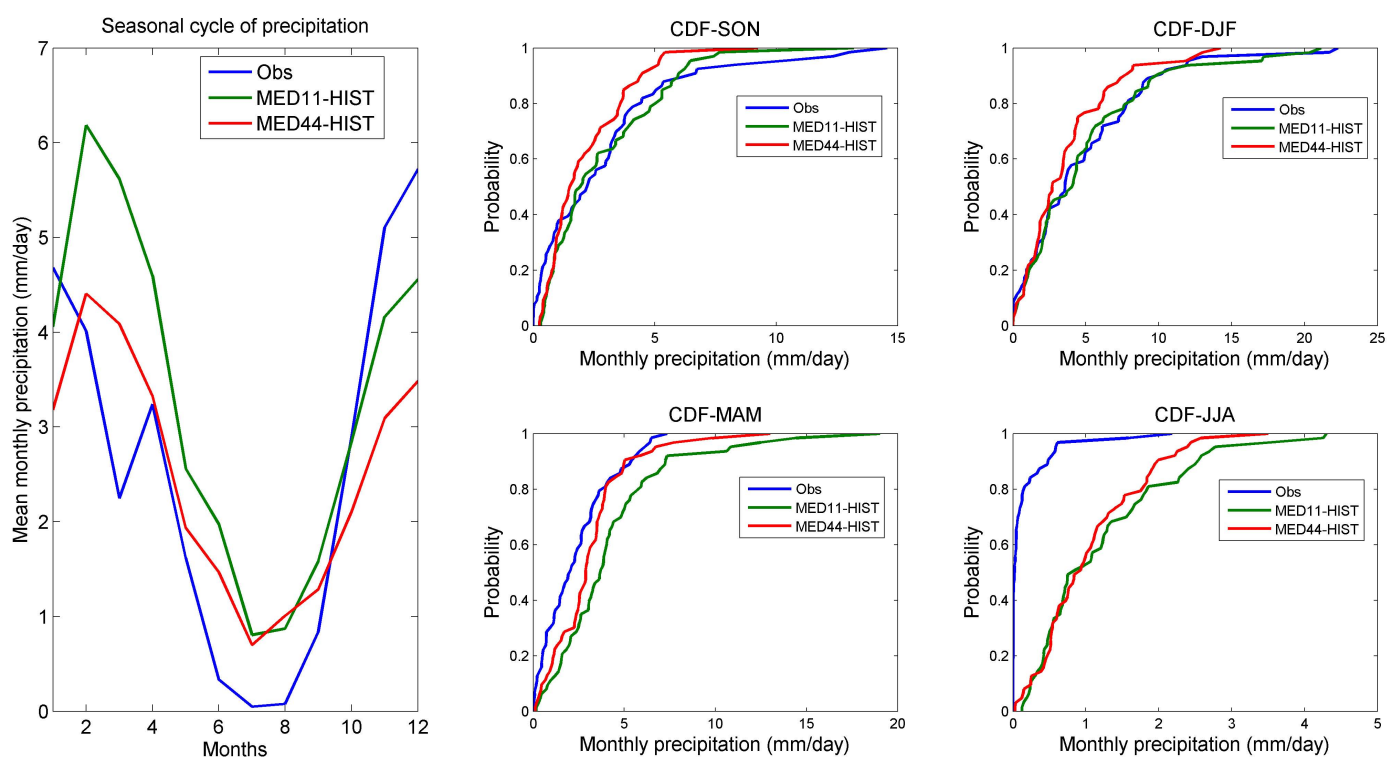

Fig. 5. Evaluation of the seasonal cycle (left panel) and seasonal distributions of monthly precipitation (right panels) of MED11-HIST and MED44-HIST (1984-2005).

the catchment scale considering a lapse rate of $-6.5^{\circ} \mathrm{C}$ per kilometer. It can be seen in Fig. 7 that both simulations driven by ERA-Interim or CNRM-CM5 are able to reproduce the seasonal cycle. The RCM runs driven by ERA-Interim are warmer than the models driven by the GCM and in better agreement with the observations. It can also be noted that the difference between the 50 and $12 \mathrm{~km}$ resolution models is weak with respect to the seasonal cycle of the bias.
The relative changes are then evaluated between the historical period 1984-2005 and a projection period 2041-2062 with the RCP4.5 and RCP8.5 emission scenarios. The projection period was chosen to start $30 \mathrm{yr}$ after the end of observed data, to show the projected changes by the mediumterm. Different time horizons have been also tested but similar results were obtained, except that the detected changes are more marked when getting closer to the year 2100 . The precipitation and temperature mean monthly cycles are presented in Fig. 8, for the historical period and the RCP4.5 and 


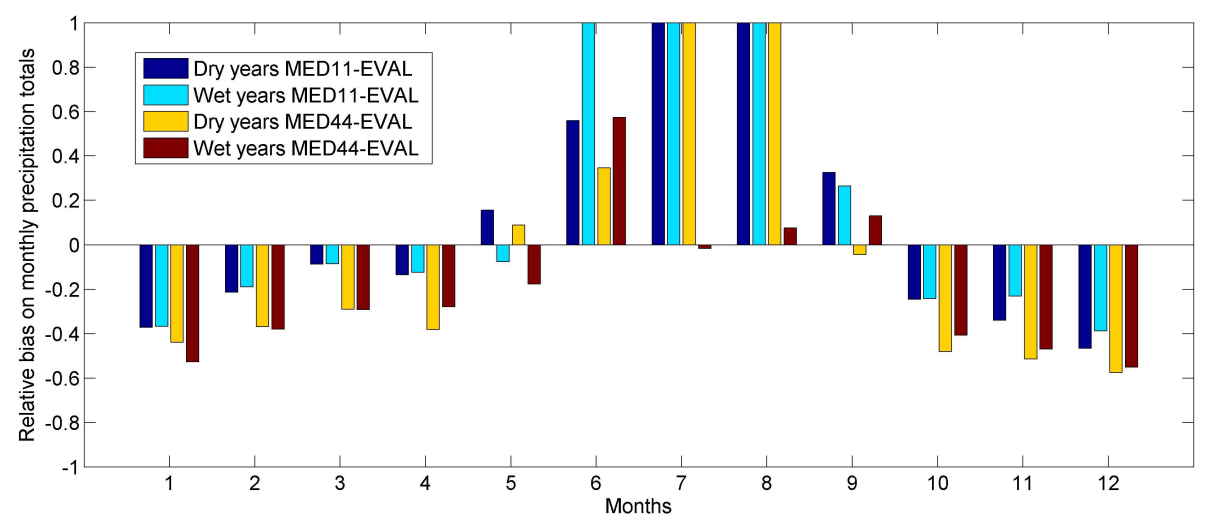

Fig. 6. Relative bias of monthly precipitation during wet and dry years, for MED11-EVAL and MED44-EVAL.

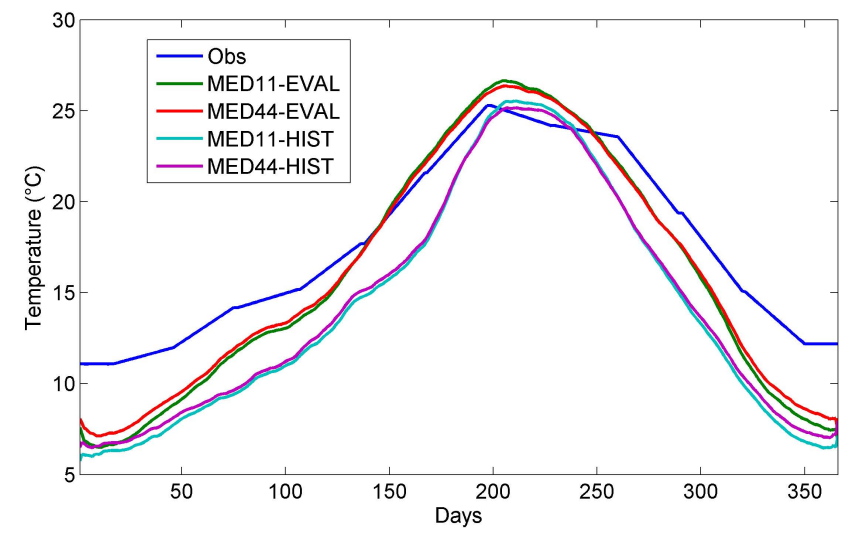

Fig. 7. Reproduction of the temperature cycle in MED11-EVAL, MED44-EVAL, MED11-HIST and MED44-HIST. The observed temperature cycle here is interpolated over the catchment considering a temperature gradient of $-6.5^{\circ} \mathrm{C} \mathrm{km}^{-1}$.

RCP8.5 scenarios at 12 and $50 \mathrm{~km}$ resolution. The climate change signal is very similar with the two models at different resolutions, depending on the scenario. For precipitation, the RCP4.5 scenario projects a decrease of $-15 \%$ of total precipitation and the RCP8.5 scenario, $-19 \%$. These changes mainly occur during the wet season (November to April), with up to $-25 \%$ of precipitation in winter under the scenario RCP8.5. For temperature, an increase of $+1.28^{\circ} \mathrm{C}$ is projected with the scenario $\mathrm{RCP} 4.5$ and $+1.87^{\circ} \mathrm{C}$ with the scenario RCP8.5. Contrary to precipitation, these changes are projected mainly during summer months. The changes on temperature are likely to have little impact on discharge, since there is almost no runoff during the summer, while, by contrast, the decease of precipitation amounts during winter months may have a critical impact on water resources.

\subsection{Hydrological modelling results}

The GR4J model is calibrated during the full period 19842010 and also on wet or dry years, according the selection
Table 2. Calibration/validation results for the hydrological model.

\begin{tabular}{lrr}
\hline Criterions & NSE & BIAS \\
\hline Whole period & 0.96 & $-0.4 \%$ \\
Wet years & 0.96 & $-2.11 \%$ \\
$\begin{array}{l}\text { Dry years } \\
\text { Validation on dry years } \\
\text { (calibration on wet years) }\end{array}$ & 0.92 & $-2.52 \%$ \\
$\begin{array}{l}\text { Validation on wet years } \\
\text { (calibration on dry years) }\end{array}$ & 0.91 & $-3.55 \%$ \\
\hline
\end{tabular}

Table 3. Calibrated model parameters.

\begin{tabular}{lcrrr}
\hline $\begin{array}{l}\text { Calibrated model } \\
\text { parameters }\end{array}$ & $x 1$ & $x 2$ & $x 3$ & $x 4$ \\
\hline Whole period & 338.86 & -0.52 & 26.00 & 1.25 \\
Wet years & 340.78 & -0.52 & 20.95 & 1.25 \\
Dry years & 380.13 & -0.21 & 7.39 & 3.20 \\
\hline
\end{tabular}

based on Fig. 3. The simulated monthly runoff obtained with the model calibrated on the full period 1984-2010 is shown in Fig. 9. The calibrated model parameters for the different periods are shown in Table 3 and the performance in calibration and validation for the different periods is presented in Table 2. Results show a good stability of the model parameters in between the wet and dry years (Table 3 ). Satisfactory model efficiency is obtained for both calibration and validation periods, with NSE coefficient above 0.9 and volume bias less than $5 \%$ (Table 2). The lowest performances are obtained when the model is calibrated on dry periods, as previously reported by Yapo et al. (1996) and Vaze et al. (2010). The good stability of the model performances under different climatic conditions is certainly due to the long period of record available $(27 \mathrm{yr})$ and to the absence of hydro-climatic trends during this period. Yapo et al. (1996) previously noted that $8 \mathrm{yr}$ of data was enough to obtain calibration insensitive to the period selected in Southeast USA while Vaze et 

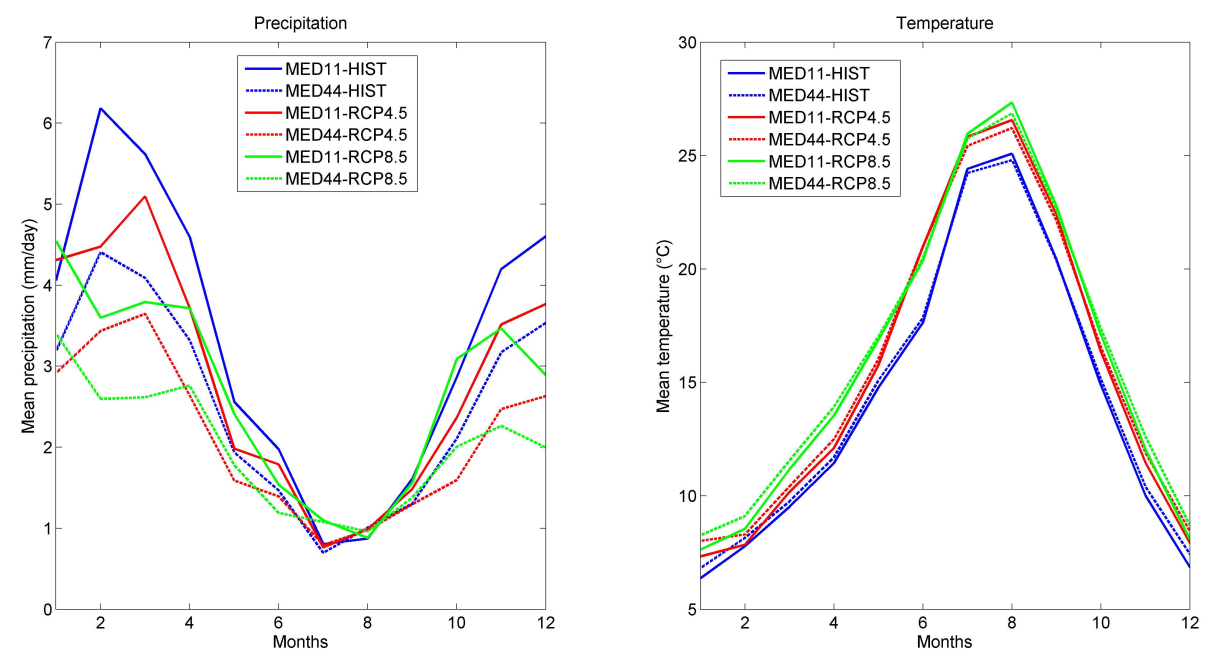

Fig. 8. Future changes on precipitation and temperature, with the RCP4.5 and RCP8.5 scenarios, between the historical period 1984-2005 and the projection period 2041-2062.

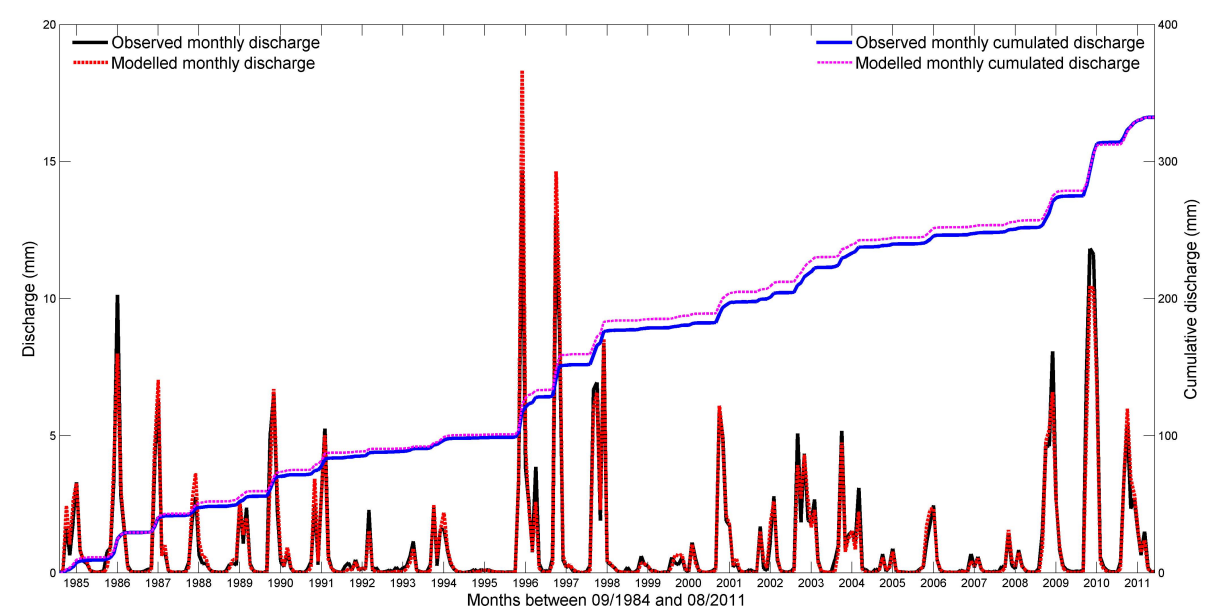

Fig. 9. Simulated discharge over the period 1984-2011 with observed precipitation and potential evapotranspiration.

al. (2010) reported the need for at least $20 \mathrm{yr}$ of data in South Australia to reach the same goal. Indeed, in semi-arid catchments, where precipitation shows a strong interannual variability, there is a need for longer periods of records to capture the whole range of variability that can be observed.

To evaluate the need of bias correction for the RCM outputs, the hydrological model is run with the uncorrected daily outputs of precipitation from the different RCM simulations, using the set of parameters obtained by calibration with observed precipitation during the full period 1984-2010. The results are presented on Fig. 10, showing that raw RCM data of precipitation are unable to reproduce with a good accuracy the seasonal cycle of discharge. All the hydrological simulations driven by RCM precipitation reproduce the dry season from June to October; however in most cases there is a severe underestimation of runoff during the SON and DJF seasons, in particular with MED11-HIST and MED44-HIST. Since the comparison shown in Fig. 10 is performed with the set of model parameters calibrated with observed precipitation, the possibility to recalibrate the hydrological model to compensate for the bias of RCM precipitation was also tested. Relative satisfactory results in calibration were obtained with the precipitation from the RCM driven by ERA, with NSE coefficients of respectively 0.9 and 0.87 for the RCM at 12 and $50 \mathrm{~km}$ resolution, with a bias lower than $4 \%$. However the performance in validation using SST or DSST is poor, with the bias on runoff volume reaching $20 \%$. In addition, the recalibrated model parameters are very different than those obtained with observed precipitation. It can be argued that even though it is not a physical model (i.e. with its parameters related to measurable physical processes), strong deviations from the set of parameters obtained with observed precipitation make the validity of the calibrated parameters questionable. The model parameters compensate for the precipitation 


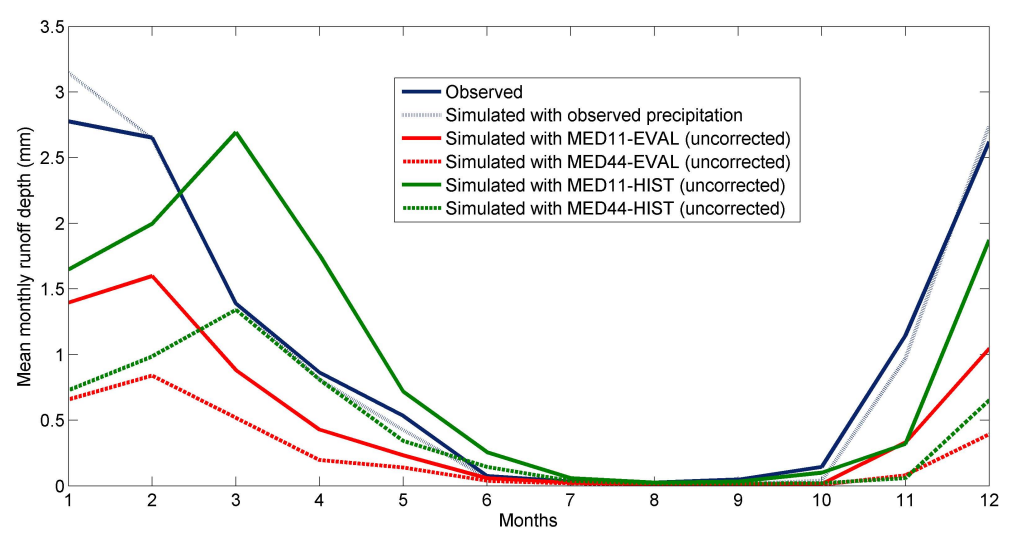

Fig. 10. Mean monthly runoff simulated with observed and RCM precipitation (uncorrected).

bias in the RCM simulations, thus proving unfeasible parameter values resulting in a loss of hydrological processes representation.

\subsection{Validation of the precipitation bias correction method}

Since the raw RCM outputs of precipitation cannot reproduce the discharge when used in the hydrological model, there is a need to correct their bias, or alternatively use a perturbation approach, prior to make future runoff scenarios. By construction, with the non-parametric approach for bias-correction considered in the present study, the distribution after correction is identical to the observed distribution during the calibration period. The main assumption of the approach is the stationarity in time of the transformation used to corrected RCM data, i.e. for different time periods or in between time periods of contrasted climatic situations. The stationarity of the bias is first tested with a standard SST: the bias correction method is calibrated for each month on the hydrological years 1984-1997 (14 yr) and validated on 1998-2010 (13 yr). The goal is to evaluate if the bias corrected outputs of precipitation from the RCM match the observed precipitation during a validation period different than the calibration period. For the sake of brevity, the results are presented for MED11-EVAL, since it is the simulation closest to the observed precipitation, but similar results are obtained with MED44-EVAL. Figure 11 shows the quantilesquantiles plots in validation: significant differences are found even after bias correction in particular for high precipitation quantiles during the wettest months. According to the Kolmorogov-smirnov test, at the $5 \%$ confidence level, the null hypothesis is rejected for the months of January, March, April, August, September and November (Table 4). Similar conclusions are reached with different calibration and validation samples ( $2 / 3$ for calibration, $1 / 3$ for validation), since the choice of the calibration period could add uncertainties (Lafon et al., 2012), or when considering seasonal bias correction functions.
In addition, a DSST is also considered in a similar way than for the hydrological model, between dry and wet periods. This test can be performed here since, except for summer months, the bias of the model is similar between dry and wet periods (Fig. 6), and the RCM simulations driven by ERA Interim (MED11-EVAL and MED44-EVAL) are able to reproduce the inter-annual variability of precipitation. Table 3 indicate that when the bias correction is calibrated on wet years and validated on dry years, it produces biascorrected distributions significantly different than those observed for most months ( 9 out of 12). On the opposite, better results are obtained when calibrating the bias-correction on dry years. The impacts on discharge are shown on Fig. 12, with the GR4J model driven by observed and bias-corrected MED11-EVAL precipitation during wet and dry years. It can be seen that the discharge is not reproduced adequately when the bias-correction is validated on dryer years than those of the calibration sample. Since future projections indicate a decrease of precipitation (Fig. 8), such bias correction method is questionable in this type of semi-arid catchments. These results are consistent with the conclusions of Maraun (2012) obtained with pseudo-reality experiments. It must be noted that in semi-arid climates with a strong variability of precipitation, longer series might be needed to biascorrect RCM outputs in a robust way as previously stated by Vrac et al. (2012), in particular for summer months with a high number of dry days. Results indicate that for the present catchment $27 \mathrm{yr}$ may not be sufficient to obtain a robust biascorrection of precipitation.

\subsection{Projected hydrological changes with the quantile perturbation method}

Since the bias-correction of precipitation cannot be validated under changing climatic conditions, the future projections were carried out only with the quantile-perturbation approach that does not rely on any stationarity hypothesis. One future period 2041-2062 is considered, with the RCM simulations at 12 and $50 \mathrm{~km}$ under the RCP4.5 and RCP8.5 

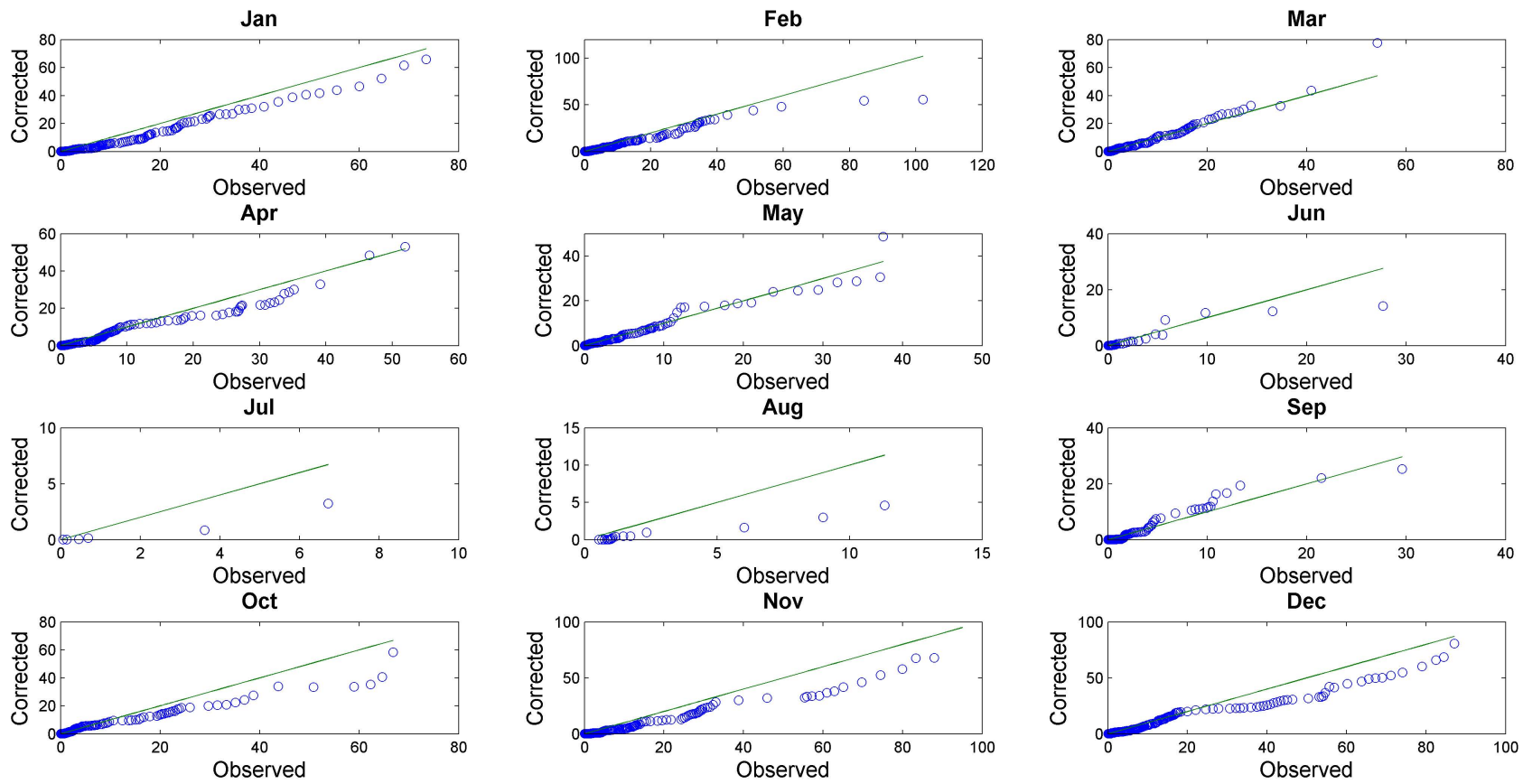

Fig. 11. Quantiles-quantiles plots between daily observed precipitation and bias-corrected precipitation from MED11-EVAL during the validation period 1998-2010.
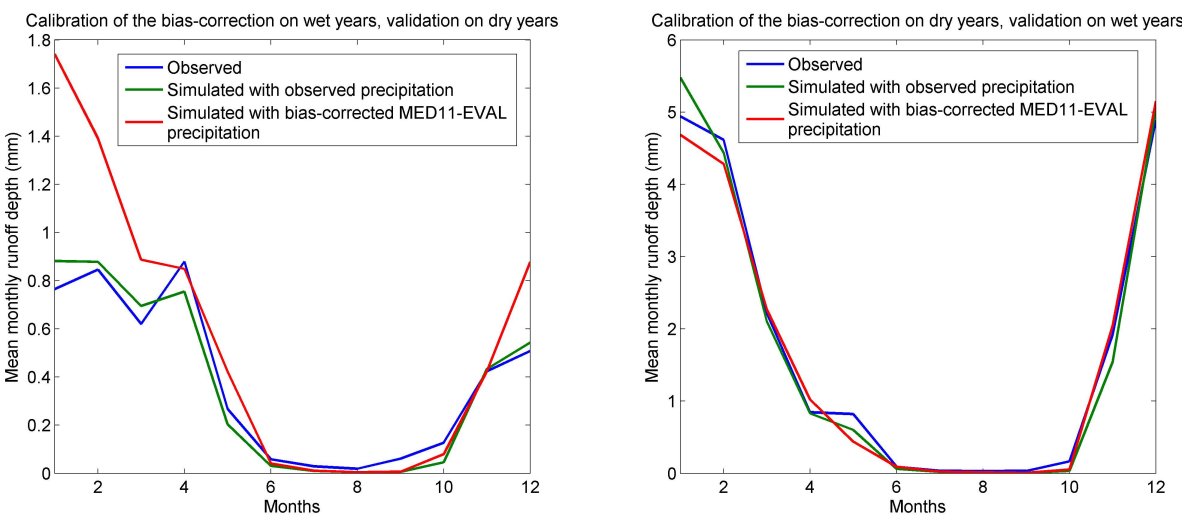

Fig. 12. Discharge simulations obtained with observed and bias-corrected precipitation form MED11-EVAL during dry (left panel) and wet years (right panel).

emission scenarios. The model projections indicate dryer and hotter conditions for the future (Fig. 8), consequently here two sets of parameters are considered to evaluate the hydrological impacts with the GR4J model: The first set consists in the parameters obtained using the whole observation period for calibration (Table 3), the second set consists in the parameters obtained in calibration with dry years only. This allows evaluating the differences in the climate change signal that could be obtained with different sets of model parameters. The times-series of observed precipitation are perturbed months by months using the quantile-perturbation method described in Sect. 3.2.2. The PE is also perturbed by monthly change factors on temperature.
Figure 13 shows the change factors obtained each month, when perturbing the observed precipitation by the change between the MED11-HIST (1984-2005) and MED11-RCP4.5 (2041-2062) simulations, for scenario RCP4.5, and by the change between the MED11-HIST and MED11-RCP8.5 simulations, for the scenario RCP8.5 and the same periods as for RCP4.5. The changes in the magnitude of the precipitation quantiles are also accompanied with a change in the number of wet days, that are reduced in both scenarios as low as $-25 \%$ (Fig. 14). Very similar results are obtained with the simulations at the $50 \mathrm{~km}$ resolution (not shown here). It can be seen that the changes are very different depending on the months and the different precipitation quantiles. This implies 

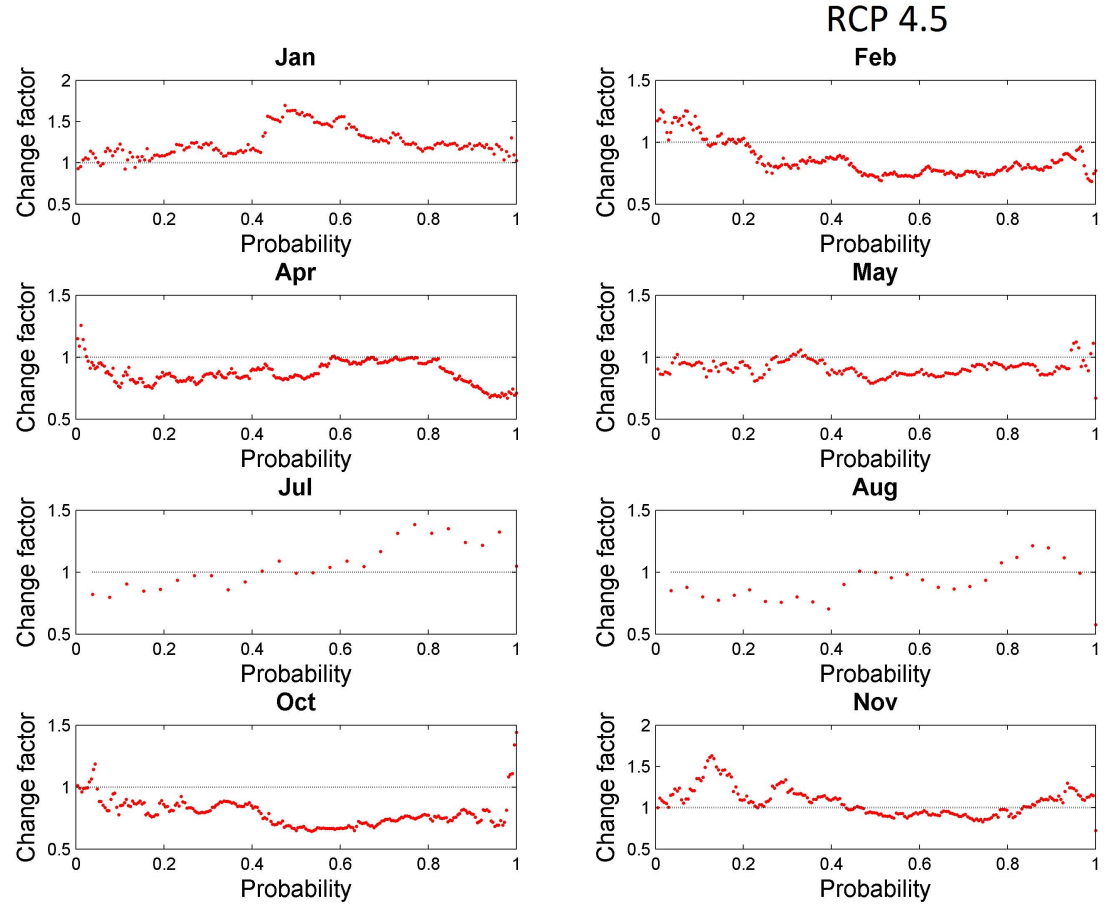

RCP 8.5
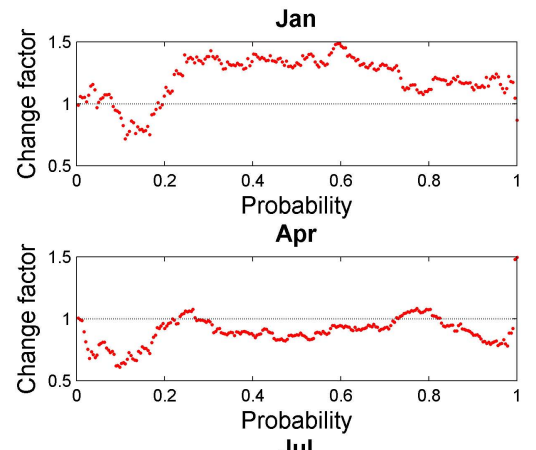

Jul

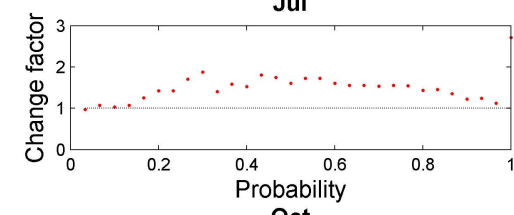

Oct

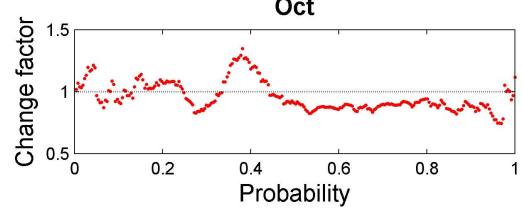

Feb

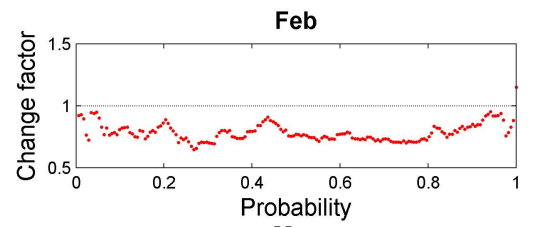

May

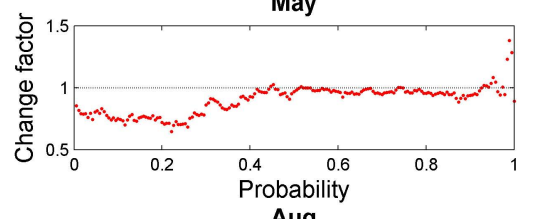

Aug

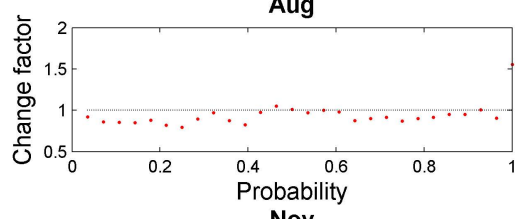

Nov

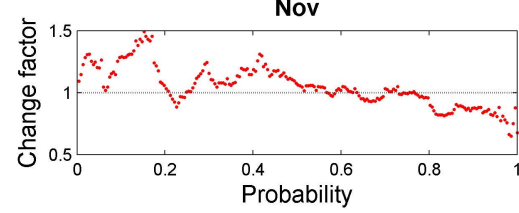

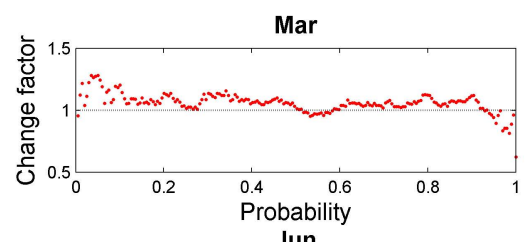

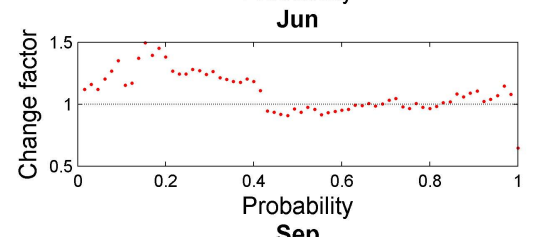

Sep
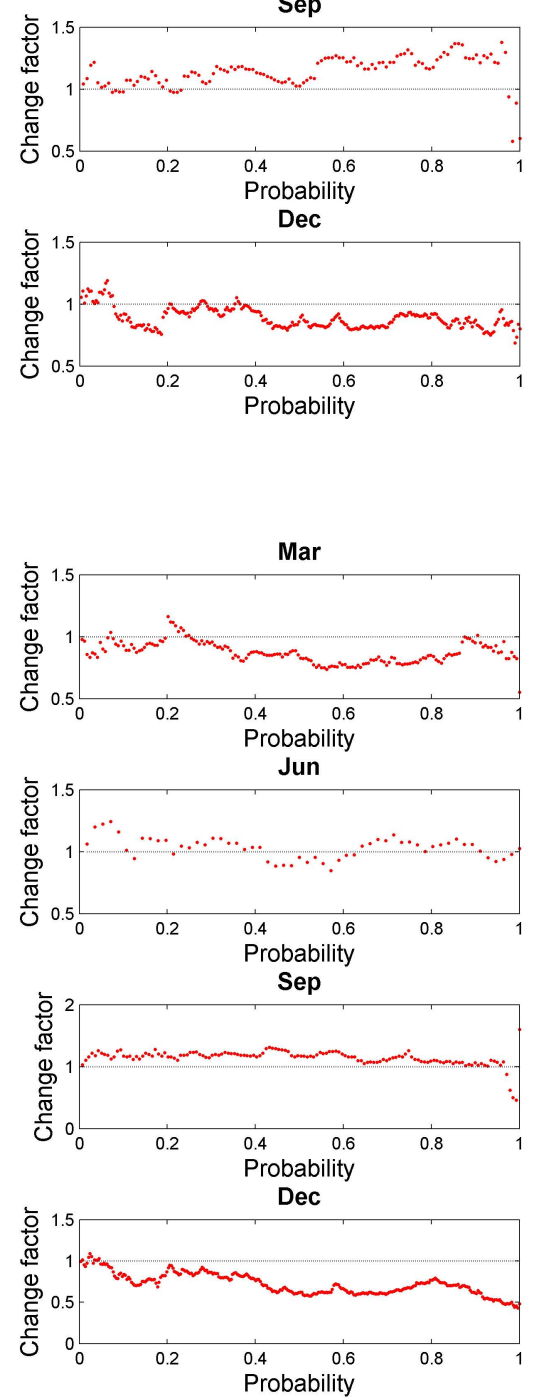

Fig. 13. Change factors on daily precipitation quantiles obtained each month between MED11-HIST and MED11-RCP4.5 (top panel), MED11-HIST and MED11-RCP8.5 (bottom panel). The historical period is 1984-2005 and the projection period is 2041-2062.

that projected changes are different for different precipitation intensities; therefore a mean change here would lead to severe under- or over- estimation. By comparison to the widely used delta change method on monthly means, the quantile perturbation method at the daily time step allows evaluating the changes in precipitation extremes (Chiew et al., 2009; Liu et al., 2011). It is particularly relevant in the present catchment, since in most months the $10 \%$ largest daily precipitation events contribute for more than $50 \%$ of total precipitation. Here a decrease in high quantiles of precipitation are 


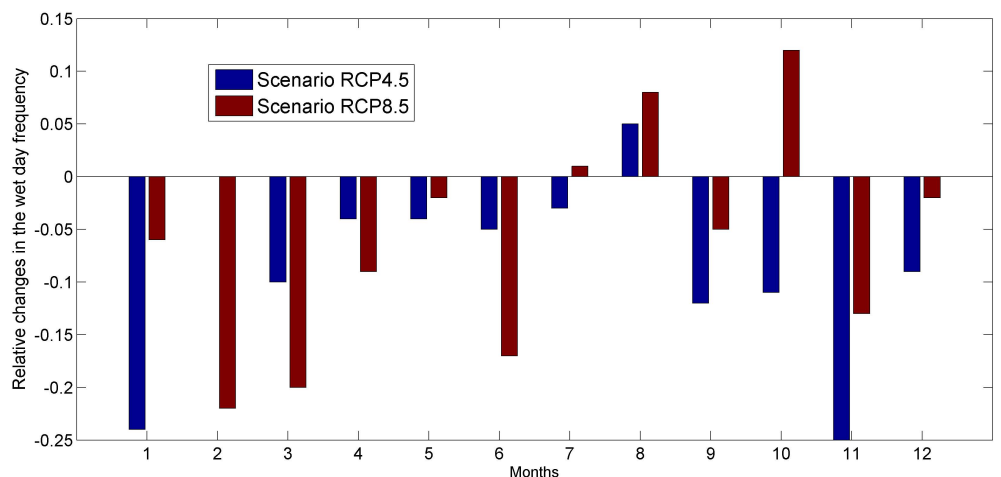

Fig. 14. Relative changes between 1984-2005 and 2041-2062 in the wet day frequency under the RCP4.5 and RCP8.5 scenarios.
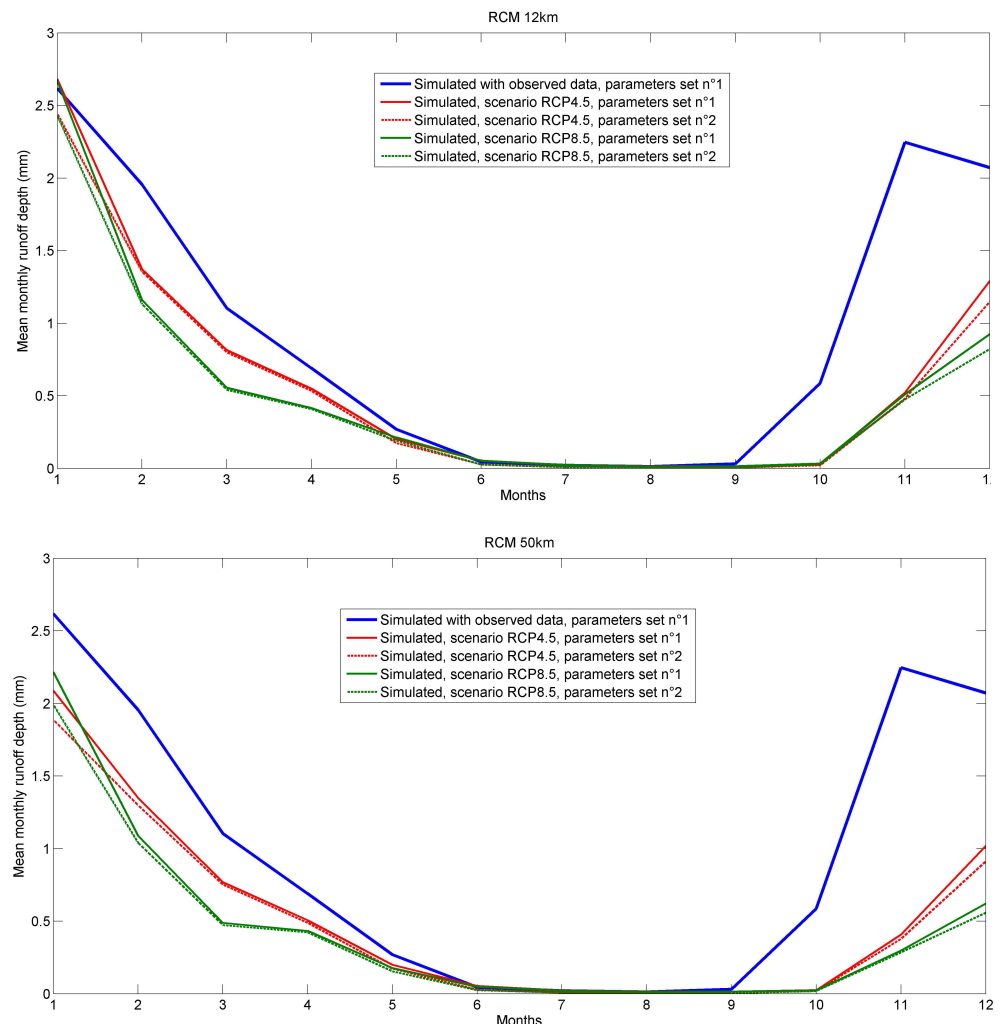

Fig. 15. Projected changes on runoff under scenarios 4.5 and 8.5 for the period 2041-2062 (the parameter set no. 1 is the one obtained when calibrating the hydrological model on all years, the parameters set no. 2 is the set obtained on calibration during dry years).

projected for the months of February, March, April, September, October, November and December, with both scenarios. Tramblay et al. (2012a) also noticed a decrease of precipitation extremes under the future scenario A1B over North Morocco.

These changes are translated into the hydrological model by a $30 \%$ decrease of runoff with the scenario RCP4.5 and $50 \%$ with the scenario RCP8.5 with the RCM at $12 \mathrm{~km}$, and respectively 35 and $57 \%$ with the RCM at $50 \mathrm{~km}$ (Fig. 14). These resulting hydrological changes are the consequences of the modifications in both precipitation intensity and the se- quence of dry and wet days. Both scenarios indicate a large decrease in surface water resources mostly during the wet season and the signal is more important with the RCM at $50 \mathrm{~km}$ (Fig. 15). The climate change signal from the RCM simulations at different resolutions has a similar impact on the hydrological simulations even if their performances in reproducing the observed climate differ. The projected changes exceed by far the uncertainties of the model bias in present climate (less than $5 \%$ ). The impact of different model parameters on projections is small (Fig. 15) even if the $x 1$ parameter, the capacity of the production reservoir, is more 
Table 4. $p$ values of the Kolmorogov-smirnov test obtained after bias-correction of MED11-EVAL precipitation (values in bold indicate significant differences, at the $5 \%$ level, between the observed and bias-corrected daily distributions).

\begin{tabular}{llll}
\hline Months & $\begin{array}{l}\text { Calibration } \\
\text { on wet years, } \\
\text { validation on } \\
\text { dry years }\end{array}$ & $\begin{array}{l}\text { Calibration } \\
\text { on dry years, } \\
\text { validation on } \\
\text { wet years }\end{array}$ & $\begin{array}{l}\text { Calibration on } \\
1984-1997, \\
\text { validation on } \\
1998-2010\end{array}$ \\
\hline Jan & $\mathbf{1 . 4 0} \times \mathbf{1 0}^{-4}$ & 0.23 & $\mathbf{0 . 0 1}$ \\
Feb & $\mathbf{1 . 0 8} \times \mathbf{1 0}^{-7}$ & $\mathbf{0 . 0 0}$ & 0.22 \\
Mar & $\mathbf{0 . 0 0}$ & 0.10 & 0.29 \\
Apr & $1.55 \times 10^{-1}$ & 0.83 & $\mathbf{0 . 0 3}$ \\
May & $\mathbf{0 . 0 3}$ & 0.44 & 0.39 \\
Jun & $\mathbf{0 . 0 2}$ & 0.80 & 0.21 \\
Jul & 0.28 & 0.96 & 0.30 \\
Aug & $\mathbf{0 . 0 1}$ & $\mathbf{7 . 7 6} \times \mathbf{1 0}^{-6}$ & $\mathbf{4 . 1 3} \times \mathbf{1 0}^{-5}$ \\
Sep & $\mathbf{0 , 0 0}$ & $1.16 \times 10^{-1}$ & $\mathbf{1 . 9 5} \times \mathbf{1 0}^{-5}$ \\
Oct & 0.16 & $\mathbf{0 . 0 4}$ & 0.06 \\
Nov & $\mathbf{2 . 0 2} \times \mathbf{1 0}^{-5}$ & $\mathbf{0 . 0 4}$ & $\mathbf{4 . 2 5} \times \mathbf{1 0}^{-5}$ \\
Dec & $\mathbf{1 . 4 7} \times \mathbf{1 0}^{-9}$ & 0.06 & 0.07 \\
\hline
\end{tabular}

important for the set 2 (dry period, $x 1=380.13$ ) than for the set 1 (whole period, $x 1=338.86$ ).

\section{Conclusions and perspectives}

This study provides the first evaluation for hydrological impact studies of one of the high-resolution RCM simulations available in framework of the Med-CORDEX initiative: the new version of the ALADIN-Climate model at two resolutions, 12 and $50 \mathrm{~km}$, with the lateral boundary conditions provided by ERA-Interim and the CNRM-CM5 GCM for the historical period and the scenarios RCP4.5 and 8.5. The main conclusion that could be drawn is that high resolution simulations at $12 \mathrm{~km}$ allow to better reproduce the seasonal patterns, the seasonal distributions and the extreme events of precipitation. Indeed, the adequate representation of precipitation by climate models is a challenging task in the Mediterranean region with a strong spatial and temporal variability and where monthly or seasonal totals are often driven by extreme events, in particular in its southernmost shores. Therefore this new generation of high-resolution regional climate model simulations allows a better representation of this variability. For temperature, the comparison was limited here since only monthly observed data were available but all simulations were able to reproduce the annual cycle. However, when the un-corrected precipitation and temperature from the climate model simulations at both resolutions are used as input of the hydrological model, they do not reproduce with enough adequacies the hydrological response. Even with the high resolution simulations, there is still a significant bias in precipitation that precludes their direct use in a hydrological model. As a consequence, there is a need for an additional step in order to use them in hydrological impact studies.

The parameters of the GR4J hydrological model at the monthly time step did not show a significant variability between dry and wet calibration periods in the catchment studied; robust results were obtained at the monthly scale, which is relevant for water resources management. Numerous studies have warned about the calibration of conceptual models for studies of climate change. Nevertheless, the fact remains that these findings are site-dependent and model-dependent. In our case study, using a model evaluated at the monthly time step during a long period ( $27 \mathrm{yr}$ ), the results of calibration and validation show high stability over time, even between two radically different sets of years $(-45 \%$ difference in precipitation between dry and wet years) that are more different than the projected changes in precipitation $(-19 \%$ in precipitation projected for the period 2041-2062 under the scenario RCP8.5). However the possible changes in land use are not considered here, neither in the RCM nor in the hydrological model. They could have a strong impact on the rainfall-runoff relationship and PE in the future, if significant changes in land use or land cover are experienced. In the present catchment, located away from urban centers and mostly agricultural and inhabited, they are not expected to change greatly, since they did not change over the last $30 \mathrm{yr}$ due to the dam construction precluding urbanization.

Results indicate that even with the high resolution model $(12 \mathrm{~km})$, forced by reanalysis data, the bias correction of precipitation by quantile-matching does not give satisfactory results during validation by the hydrological model. If quantile mapping correction techniques performed well in temperate or continental climates (Themeß1 et al., 2011; Lafon et al., 2012), this is not the case in semi-arid regions (Maraun, 2012). There is a need for improved bias correction techniques, adapted to the semi-arid climates characterized by a strong inter-annual variability and the importance of extreme events. In particular quantile mapping methods suffer from different drawbacks that could be critical in semi-arid regions: there is no physical consistency between the different corrected variables, as for example temperature and precipitation, when such consistency exists in the GCM and RCM simulations (Quintana Seguí et al., 2010). In addition, it does not distinguish the origin of the bias and neglect feedback mechanisms such as changes in atmospheric circulation patterns, which could affect the stationarity of the standard bias-correction methods (Driouech et al., 2010; Ehret et al., 2012).

Therefore, a quantile perturbation approach was introduced for scenario building, which made it possible to account for the changes in various moments of the distribution. It allowed reproducing the possible changes induced by a modification of extreme events, which have a large contribution to precipitation total amounts in this catchment. Future hydrological changes were projected with this quantile perturbation approach providing ensembles of perturbed series. 
The climate change signal with scenarios 4.5 and 8.5 shows a decrease from -30 to $-57 \%$ in surface runoff for $2041-$ 2062, when for the same period the projections for precipitation ranges between -15 and $-19 \%$ and for temperature are expecting to rise between +1.3 and $+1.9^{\circ} \mathrm{C}$. Using the quantile perturbation method, similar projections are obtained with the model at the resolutions of 12 and $50 \mathrm{~km}$, but the changes are more pronounced with the model at $50 \mathrm{~km}$. Therefore, the RCM bias in present climate has an influence on the projected changes. The projected changes could have a strong negative impact on the water resources in this region and results obtained in the present study are consistent with previous studies in the same region (Schilling et al., 2012; Milano et al., 2012, 2013). Further work should now test other approaches to evaluate the climate change signal and compare the results with those obtained in the present study. In particular other types of bias-correction methods and hydrological models should be considered but also the use of RCM with an improved description of the present-climate hydrological cycle (improved mean behavior and extreme events)

We are however aware that individual RCM simulations do not allow to take into account two of the main sources of uncertainty in regional climate change, that is to say the choice of the RCM and the choice of the forcing GCM (Déqué et al., 2012). This will be possible in the future with the extension of the number of Med-CORDEX simulations and database (www.medcordex.eu): coordinated 15 scenario simulations at $50-\mathrm{km}$ and 6 scenario simulations at $12-\mathrm{km}$ are planned within the coming years. Therefore in the near future, more Med-CORDEX simulations will be available to provide multimodel ensembles allowing to tackle, for example, the model choice uncertainty (GCM and RCM) or the model physics choice for a given model. Then hydrological impact studies could be undertaken across the Mediterranean basin considering this ensemble of high-resolution simulations to provide a robust diagnostic of the future projections.

Acknowledgements. The observed data was provided by the department of Water Research and Planning (DRPE) of Morocco and the Hydraulic Basin Agency of Loukkos-Tétouan. We thank A. Alias (CNRM) for running the Mediterranean ALADIN simulations. This work is a contribution to the HyMeX program (HYdrological cycle in the Mediterranean Experiment) through INSU-MISTRALS support and to the Med-CORDEX initiative (COordinated Regional climate Downscaling EXperiment - Mediterranean region). The third author has received funding from the French National Research Agency (ANR) project REMEMBER (contract ANR-12SENV-001) and from the European Commission through the FP7 CLIM-RUN project. The ALADIN simulations used in the current work can be downloaded from the Med-CORDEX database (www. medcordex.eu) maintained by ENEA (special thanks to E. Lombardi). The authors would like to thank the Handling Editor, S. Attinger and also the three anonymous reviewers for their helpful comments.
Edited by: S. Attinger

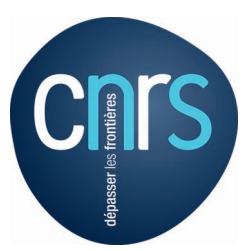

The publication of this article is financed by CNRS-INSU.

\section{References}

Anandhi, A., Frei, A., Pierson, D. C., Schneiderman, E. M., Zion, M. S., Lounsbury, D., and Matonse, A. H.: Examination of change factor methodologies for climate change impact assessment, Water Resour. Res., 47, W03501, doi:10.1029/2010WR009104, 2011.

Born, K., Fink, A. H., and Paeth, H.: Dry and wet periods in the northwestern Maghreb for present day and future climate conditions, Meteorol. Z., 17, 533-551, 2008.

Bouaicha, R. and Benabdelfadel, A.: Variabilité et gestion des eaux de surface au Maroc, Sécheresse, 21, 1-5, 2010.

Boudhar, A., Duchemin, B., Hanich, L., Boulet, G., and Chehbouni, A.: Spatial distribution of the air temperature in mountainous areas using satellite thermal infra-red data, C. R. Geosci., 343, 32 42, 2010.

Chiew, F. H. S., Teng, J., Vaze, J., Post, D. A., Perraud, J. M., Kirono, D. G. C., and Viney, N. R.: Estimating climate change impact on runoff across southeast Australia: Method, results, and implications of the modeling method, Water Resour. Res., 45, W10414, doi:10.1029/2008WR007338, 2009.

Christensen, J. H., Kjellström, E., Giorgi, F., Lenderink, G., and Rummukainen, M.: Weight assignment in regional climate models, Clim. Res., 44, 179-194, doi:10.3354/cr00916, 2010.

Colin, J., Déqué, M., Radu, R., and Somot, S.: Sensitivity study of heavy precipitations in Limited Area Model climate simulation: influence of the size of the domain and the use of the spectral nudging technique, Tellus, 62A, 591-604, 2010.

Coron, L., Andréassian, V., Perrin, C., Lerat, J., Vaze, J., Bourqui, M., and Hendrickx, F.: Crash testing hydrological models in contrasted climate conditions: an experiment on 216 Australian catchments, Water Resour. Res., 48, W05552, doi:10.1029/2011WR011721, 2012.

Dee, D. P., Uppala, S. M., Simmons, A. J., Berrisford, P., Poli, P., Kobayashi, S., Andrae, U., Balmaseda, M. A., Balsamo, G., Bauer, P., Bechtold, P., Beljaars, A. C. M., van de Berg, L., Bidlot, J., Bormann, N., Delsol, C., Dragani, R., Fuentes, M., Geer, A. J., Haimberger, L., Healy, S. B., Hersbach, H., Hólm, E. V., Isaksen, L., Kållberg, P., Köhler, M., Matricardi, M., McNally, A. P., Monge-Sanz, B. M., Morcrette, J.-J., Park, B.-K., Peubey, C., de Rosnay, P., Tavolato, C., Thépaut, J.-N., and Vitart, F.: The ERA-Interim reanalysis: configuration and performance of the data assimilation system, Q. J. Roy. Meteorol. Soc., 137, 553597, doi:10.1002/qj.828, 2011.

Déqué, M.: Frequency of precipitation and temperature extremes over France in an anthropogenic scenario: Model results and statistical correction according to observed values, Global Planet. Change, 57, 16-26, 2007. 
Déqué, M.: Regional climate simulation with a mosaic of RCMs, Meteorol. Z., 19, 259-266, doi:10.1127/0941-2948/2010/0455, 2010.

Déqué, M. and Somot, S.: Extreme precipitation and high resolution with Aladin, Idöjaras, Q. J. Hungar. Meteorol. Serv., 112, 179190, 2008.

Déqué, M., Somot, S., Sanchez-Gomez, E., Goodess, C. M., Jacob, D., Lenderink, G., and Christensen, O. B.: The spread amongst ENSEMBLES regional scenarios: Regional Climate Models, driving General Circulation Models and interannual variability, Clim. Dynam., 38, 951-964, doi:10.1007/s00382-011-1053-x, 2012.

Driouech, F., Déqué, M., and Mokssit, A.: Numerical simulation of the probability distribution function of precipitation over Morocco, Clim. Dynam., 32, 1055-1063, 2009.

Driouech, F., Déqué, M., and Sánchez-Gómez, E.: Weather regimes-Moroccan precipitation link in a regional climate change simulation, Global Planet. Change, 72, 1-10, 2010.

Dubois, C., Somot, S., Calmanti, S., Carillo, A., Déqué, M., Dell'Aquilla, A., Elizalde-Arellano, A., Gualdi, S., Jacob, D., Lheveder, B., Li, L., Oddo, P., Sannino, G., Scoccimarro, E., and Sevault, F.: Future projections of the surface heat and water budgets of the Mediterranean sea in an ensemble of coupled atmosphere-ocean regional climate models, Clim. Dynam., 39, 1859-1884, doi:10.1007/s00382-011-1261-4, 2012.

Ehret, U., Zehe, E., Wulfmeyer, V., Warrach-Sagi, K., and Liebert, J.: HESS Opinions "Should we apply bias correction to global and regional climate model data?", Hydrol. Earth Syst. Sci., 16, 3391-3404, doi:10.5194/hess-16-3391-2012, 2012.

Esper, J., Frank, D., Büntgen, U., Verstege, A., Luterbacher, J., and Xoplaki, E.: Long-term drought severity variations in Morocco, Geophys. Res. Lett., 34, L17702, doi:10.1029/2007GL030844, 2007.

Etchevers, P., Golaz, C., Habets, F., and Noilhan, J.: Impact of a climate change on the Rhone river catchment hydrology, J. Geophys. Res., 107, ACL 6-1-ACL 6-18, doi:10.1029/2001JD000490, 2002.

Fowler, H. J., Blenkinsop, S., and Tebaldi, C.: Linking climate change modelling to impacts studies: recent advances in downscaling techniques for hydrological modelling, Int. J. Climatol., 27, 1547-1578, 2007.

Gao, X., Pal, J. S., and Giorgi, F.: Projected changes in mean and extreme precipitation over the Mediterranean region from high resolution double nested RCM simulation, Geophys. Res. Lett. 33, L03706, doi:10.1029/2005GL024954, 2006.

Gibelin, A. L. and Déqué, M.: Anthropogenic climate change over the Mediterranean region simulated by a global variable resolution model, Clim. Dynam. 20, 327-339, 2003.

Giorgi, F.: Climate change hot-spots, Geophys. Res. Lett., 33, L08707, doi:10.1029/2006GL025734, 2006.

Giorgi, F. and Lionello, P.: Climate change projections for the Mediterranean region, Global Planet. Change, 63, 90-104, 2008.

Giorgi, F., Jones, C., and Asrar, G. R.: Addressing climate information needs at the regional level: the CORDEX framework, WMO Bull., 58, 175-183, 2009.

Herrmann, M., Somot, S., Calmanti, S., Dubois, C., and Sevault, F.: Representation of spatial and temporal variability of daily wind speed and of intense wind events over the Mediterranean Sea using dynamical downscaling: impact of the regional climate model configuration, Nat. Hazards Earth Syst. Sci., 11, 19832001, doi:10.5194/nhess-11-1983-2011, 2011.

Kay, A. L. and Davies, H. N.: Calculating potential evaporation from climate model data: A source of uncertainty for hydrological climate change impacts, J. Hydrol., 358, 221-239, 2008.

Klemeš, V.: Operational testing of hydrological simulation models, Hydrolog. Sci. J., 31, 13-24, 1986.

Knippertz, P., Christoph, M., and Speth, P.: Long-term precipitation variability in Morocco and the link to the large-scale circulation in recent and future climates, Meteorol. Atmos. Phys., 83, 67-88, 2003.

Lafon, T., Dadson, S., Buys, G., and Prudhomme, C.: Bias correction of daily precipitation simulated by a regional climate model: a comparison of methods, Int. J. Climatol., 33, 13671381, doi:10.1002/joc.3518, 2013.

Lagarias, J. C., Reeds, J. A., Wright, M. H., and Wright, P. E.: Convergence Properties of the Nelder-Mead Simplex Method in Low Dimensions, SIAM J. Optimiz., 9, 112-147, 1998.

Lavaysse, C., Vrac, M., Drobinski, P., Lengaigne, M., and Vischel, T.: Statistical downscaling of the French Mediterranean climate: assessment for present and projection in an anthropogenic scenario, Nat. Hazards Earth Syst. Sci., 12, 651-670, doi:10.5194/nhess-12-651-2012, 2012.

Li, C. Z., Zhang, L., Wang, H., Zhang, Y. Q., Yu, F. L., and Yan, D. H.: The transferability of hydrological models under nonstationary climatic conditions, Hydrol. Earth Syst. Sci., 16, 1239-1254, doi:10.5194/hess-16-1239-2012, 2012.

Liu, T., Willems, P., Pan, X. L., Bao, An. M., Chen, X., Veroustraete, F., and Dong, Q. H.: Climate change impact on water resource extremes in a headwater region of the Tarim basin in China, Hydrol. Earth Syst. Sci., 15, 3511-3527, doi:10.5194/hess-15-35112011, 2011.

Majone, B., Bovolo, C. I., Bellin, A., Blenkinsop, S., and Fowler, H. J.: Modeling the impacts of future climate change on water resources for the Gallego river basin (Spain), Water Resour. Res., 48, W01512, doi:10.1029/2011WR010985, 2012.

Maraun, D.: Nonstationarities of regional climate model biases in European seasonal mean temperature and precipitation sums, Geophys. Res. Lett., 39, L06706, doi:10.1029/2012GL051210, 2012.

Maraun, D., Wetterhall, F., Ireson, A. M., Chandler, R. E., Kendon, E. J., Widmann, M., Brienen, S., Rust, H. W., Sauter, T., Themeß1, M., Venema, V. K. C., Chun, K. P., Goodess, C. M., Jones, R. G., Onof, C., Vrac, M., and Thiele-Eich, I.: Precipitation downscaling under climate change: Recent developments to bridge the gap between dynamical models and the end user, Rev. Geophys., 48, RG3003, doi:10.1029/2009RG000314, 2010.

Michelangeli, P.-A., Vrac, M., and Loukos, H.:Probabilistic downscaling approaches: Application to wind cumulative distribution functions, Geophys. Res. Lett., 36, L11708, doi:10.1029/2009GL038401, 2009.

Milano, M., Ruelland, D., Fernandez, S., Dezetter, A., Fabre, J., and Servat, E.: Facing global changes in the Mediterranean basin: How could the current water stress evolve by the medium-term?, C. R. Geosci., 344, 432-440, 2012.

Milano, M., Ruelland, D., Fernandez, S., Dezetter, A., Fabre, J. Servat, E., Fritsch, J.-M., Ardoin-Bardin, S., and Thivet, G.: Current state of Mediterranean water resources and future 
trends under global changes, Hydrolog. Sci. J., 58, 498-518, doi:10.1080/02626667.2013.774458, 2013.

Oudin, L., Hervieu, F., Michel, C., Perrin, C., Andréassian, V., Anctil, F., and Loumagne, C.: Which potential evapotranspiration input for a lumped rainfall-runoff model? Part 2 - Towards a simple and efficient potential evapotranspiration model for rainfallrunoff modelling, J. Hydrol., 303, 290-306, 2005.

Patricola, C. M. and Cook, K. H.: Northern African climate at the end of the twenty-first century: an integrated application of regional and global climate models, Clim. Dynam., 35, 193-212, 2010.

Perrin, C., Michel, C., and Andréassian, V.: Improvement of a parsimonious model for streamflow simulation, J. Hydrol., 279, 275289, 2003.

Piani, C., Weedon, G. P., Best, M., Gomes, S. M., Viterbo, P., Hagemann, S., and Haerter, J. O.: Statistical bias correction of global simulated daily precipitation and temperature for the application of hydrological models, J. Hydrol., 395, 199-215, doi:10.1016/j.jhydrol.2010.10.024, 2010.

Prudhomme, C., Wilby, R. L., Crooks, S., Kay, A.,L., and Reynard, N. S.: Scenario-neutral approach to climate change impact studies: Application to flood risk, J. Hydrol., 390, 198-209, 2010.

Quintana Seguí, P., Ribes, A., Martin, E., Habets, F., and Boé, J.: Comparison of three downscaling methods in simulating the impact of climate change on the hydrology of Mediterranean basins, J. Hydrol., 383, 111-124, 2010.

Radu, R., Déqué, M., and Somot, S.: Spectral nudging in a spectral regional climate model, Tellus A, 60, 885-897, doi:10.1111/j.1600-0870.2008.00343.x, 2008.

Ragab, R. and Prudhomme, C.: Climate Change and Water Resources Management in Arid and Semi-arid Regions: Prospective and Challenges for the 21st Century, Biosyst. Eng., 81, 3-34, 2002.

Ruelland, D., Ardoin-Bardin, S., Collet, L., and Roucou, P.: Simulating future trends in hydrological regime of a large SudanoSahelian catchment under climate change, J. Hydrol., 424, 207216, 2005

Ruti, P., Somot, S., Dubois, C., Calmanti, S., Ahrens, B., Alias, A., Aznar, R., Bartholy, J., Bastin, S., Béranger, K., Brauch, J., Calvet, J.-C., Carillo, A., Decharme, B., Dell'aquila, A., Djurdjevic, V., Drobinski, P., Elizalde-Arellano, A., Gaertner, M., Galan, P., Gallardo, C., Giorgi, F., Gualdi, S., Harzallah, A., Herrmann, M., Jacob, D., Khodayar, S., Krichak, S., Lebeaupin, C., L'Heveder, B., Li, L., Liguro, G., Lionello, P., Onol, B., Rajkovic, B., Sannino, G., and Sevault, F.: MED-CORDEX initiative for Mediterranean Climate studies, B. Am. Meteorol. Soc., submitted, 2013.

Sanchez-Gomez, E., Somot, S., and Mariotti, A.: Future changes in the Mediterranean water budget projected by an ensemble of Regional Climate Models, Geophys. Res. Lett., 36, L21401, doi:10.1029/2009GL040120, 2009.

Sanchez-Gomez, E., Somot, S., Josey, S. A., Dubois, C., Elguindi, N., and Déqué, M.: Evaluation of the Mediterranean Sea Water and Heat budgets as simulated by an ensemble of high resolution Regional Climate Models, Clim. Dynam., 37, 2067-2086, doi:10.1007/s00382-011-1012-6, 2011.
Schilling, J., Freier, K. P., Hertig, E., and Scheffran, J.: Climate change, vulnerability and adaptation in North Africa with focus on Morocco, Agriculture, Ecosyst. Environ., 156, 12-26, 2012.

Senatore, A., Mendicino, G., Smiatek, G., and Kunstmann, H.: Regional climate change projections and hydrological impact analysis for a Mediterranean basin in Southern Italy, J. Hydrol., 399, 70-92, 2011.

Sperna Weiland, F. C., Tisseuil, C., Dürr, H. H., Vrac, M., and van Beek, L. P. H.: Selecting the optimal method to calculate daily global reference potential evaporation from CFSR reanalysis data for application in a hydrological model study, Hydrol. Earth Syst. Sci., 16, 983-1000, doi:10.5194/hess-16-983-2012, 2012.

Teng, J., Vaze, J., Chiew, F. H. S., Wang, B., and Perraud, J.-M.: Estimating the Relative Uncertainties Sourced from GCMs and Hydrological Models in Modeling Climate Change Impact on Runoff, J. Hydrometeorol., 13, 122-139, 2012.

Themeß1, M., Gobiet, A., and Leuprecht, A.: Empirical-statistical downscaling and error correction of daily precipitation from regional climate models, Int. J. Climatol., 31, 1531-1544, doi:10.1002/joc.2168, 2011.

Tramblay, Y., Badi, W., Driouech, F., El Adlouni, S., Neppel, L., and Servat, E.: Climate change impacts on extreme precipitation in Morocco, Global Planet. Change, 82-83, 104-114, 2012a

Tramblay, Y., Bouaicha, R., Brocca, L., Dorigo, W., Bouvier, C., Camici, S., and Servat, E.: Estimation of antecedent wetness conditions for flood modelling in northern Morocco, Hydrol. Earth Syst. Sci., 16, 4375-4386, doi:10.5194/hess-16-43752012, 2012b.

Vaze, J., Post, D. A., Chiew, F. H. S., Perraud, J. M., Viney, N. R., and Teng, J.: Climate non-stationarity - validity of calibrated rainfall-runoff models for use in climate change studies, J. Hydrol., 394, 447-457, 2010

Voldoire, A., Sanchez-Gomez, E., Salas-y-Mélia, D., Decharme, B. Cassou, C., Sénési, S., Valcke, S., Beau, I., Alias, A., Chevallier, M., Déqué, M., Deshayes, J., Douville, H., Fernandez, E., Madec, G., Maisonnave, E., Moine, M.-P., Planton, S., SaintMartin, D., Szopa, S., Tyteca, S., Alkama, R., Belamari, S., Braun, A., Coquart, L., and Chauvin, F.: The CNRM-CM5.1 global climate model: description and basic evaluation, Clim. Dynam., 40, 2091-2121, doi:10.1007/s00382-011-1259-y, 2011.

Vrac, M., Drobinski, P., Merlo, A., Herrmann, M., Lavaysse, C., Li, L., and Somot, S.: Dynamical and statistical downscaling of the French Mediterranean climate: uncertainty assessment, Nat. Hazards Earth Syst. Sci., 12, 2769-2784, doi:10.5194/nhess-122769-2012, 2012

Wilby, R. L.: Uncertainty in water resource model parameters used for climate change impact assessment, Hydrol. Process., 19, 3201-3219, 2005.

Willems, P. and Vrac, M.: Statistical precipitation downscaling for small-scale hydrological impact investigations of climate change, J. Hydrol., 402, 193-205, 2011.

Yapo, P. O., Gupta, H. V., and Sorooshian, S.: Automatic calibration of conceptual rainfall-runoff models: Sensitivity to calibration data, J. Hydrol., 181, 23-48, 1996. 